\title{
Ontological Approach Based on Multi-Agent System for Indexing and Filtering Arabic Docu- ments
}

Samia Zouaoui, Khaled Rezeg

LINFI Laboratory, Department of Computer Science

University of Biskra

Algeria

zouaoui.s9@gmail.com, rezeg_khaled@yahoo.fr

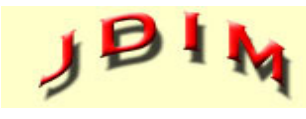

Journal of Digital

Information Management
ABSTRACT: In recent years, Automatic Natural Language Processing (ANLP) for Arabic language has received a great amount of attention for the development of several applications such as question answering, information retrieval and translation, etc. However, there are a few automated applications using Semantic Web technologies for retrieving Arabic-language documents despite the high demand and need for this content. In addition, the Arabic language presents serious challenges to researchers and developers of NLP applications. These challenges are due to the complexity of the morphological, syntactic and semantic characteristics specific to the Arabic text, which requires the use of semantic resources such as ontology. In our work, we propose a new approach based on ontology and multi-agent systems to index and filter Arabic documents. Our proposal is composed of five layers, each layer contains several agents: (1) Lexical Layer; (2) Syntactic Layer; (3) Semantic Layer; (4) Indexing Layer; and GUI/Interface Layer. Our Arabic ontology is manually constructed on the basis of schemes (الأوزان) and their semantics meanings. We use also combination of Arabic WordNet contents and Arabic VerbNet in the process of constructing the ontology. We use the semantic similarity to find the relevant documents according to the user's queries. The aim of this paper is to study the effect of patterns in solving the problem of the semantic indexing system (SIS). The main objective is to improve the quality of the indexing process to ensure the accuracy of the information search of relevant documents based on us ers' multiword queries, and also to reduce indexing and search time. Indeed, our experiments are conducted on the basis of the combination of two Arab corpus: OSAC and SemEval. We compared our results with Lucene in- dex for the same data and, we found that our approach achieves much better results than the other.

Subject Categories and Descriptors: [H.3.1 Content Analysis and Indexing]; [H.3.3 Information Search and Retrieval] ; [I.2.11 Distributed Artificial Intelligence]; Multiagent systems

General Terms: Information Retrieval, Natural Language Processing, Arabic Ontology

Keywords: Arabic Documents, Ontology, Semantic Indexing, Multi-Agent System, Information Retrieval, Semantic Similarity

Received: 17 October 2018, Revised 3 January 2019, Accepted 16 January 2019

Review Metrics: Review Scale: 0/6, Review Score: 4.8/6, Interreviewer consistency: $82.5 \%$

DOI: 10.6025/jdim/2019/17/3/145-163

\section{Introduction}

Indexing is a very important operation in the field of Natural Language Processing (NLP). It has several applications in different domains. One of these important domains is information retrieval (IR). The information contained in a document are analyzed and processed by a user or a computer to extract a set of descriptors representing this document, which is called the index. Indexes play an important role in searching the information in which they 
facilitate the comparison between the representation of a document and a query [2] by identifying the best words that can be used to find a document quickly and with less effort.

In the literature, there are two types of indexation; traditional indexing (TI) and semantic indexing (SA). TI is a method of extracting the most common used words in the text as index words to represent the document without modification or addition. However, semantic indexing (SA) consists of representing the document by the meanings of words (or concepts) rather than by keywords. Such an approach has become very interesting since it solves many word ambiguity problems [4]. The process of indexing can be conducted manually, automatically or semiautomatically [31]. However, indexing is a complex and difficult process, especially when it concerns the indexing of Arabic documents. This is due to the richness of the Arabic language at its four levels: grammatical, morphological, phonetic and semantic.

Nowadays, there have been many works done about indexing Arabic documents using different techniques and tools. Ontology is the most widely used element for indexing Arabic documents in many studies to support the semantic aspect in the various tasks of the NLP, particularly for indexing Arabic documents. It is one of the most used elements to represent the knowledge of a particular domain where it is considered as the most important foundations of Semantic Web Technologies [33]. Ontology is used to allow machines to share a common understanding of information among people or software agents [57]. Ontology can be used in several applications because it provides an explicit and formal way for shareable domain that facilitates the data understanding between people and different applications [57] in various fields, such as artificial intelligence, computer science and linguistics. In 1993, Gruber defined the term of ontology as "a specification of a representational vocabulary for a shared domain of discourse definitions of classes, relations, functions, constraints and objects" [29]. Therefore, the goal of domain ontology is to represent knowledge of a particular area of interest in a formal manner easy to be understood by both human and computer.

The literature on semantic web shows a variety of approaches which uses Ontology to process the English language-based documents. However, there are few works that treat the documents written in Arabic language [12]. This is due to the complex morphological and semantic structures of the Arabic language see $[53,17]$. One of the most effective methods for indexing Arabic documents is developing processes that associate information to another. While this method plays a vital role in some applications, most of the research conducted in the area still has not provided satisfactory results. Therefore, there is a need for Arabic Ontology-based Information Retrieval systems.

There has been little research in the area of Ontology- based Information Retrieval, particularly in Arabic language; This was with more or less satisfactory results because of the challenging constraints of complex morphological and semantic structures. Indexing documents causes much more challenges particularly in the case of searching semantics where the user enters a query using natural language to the system because we do not need the user to help the indexing or even technically to be aware of the indexing process.

For the semantic indexing of Arabic documents, we are building a new ontology (SchemNet) based on Arabic schemes and their meanings and the combination of the contents of Arabic WordNet (AWN)[22, 24] and Arabic VerbNet (AVN)[38]. We noticed that Arabic schemes and their meanings were not used in AWN and AVN despite their great importance in Arabic. This article proposes the use of the Arabic ontology (SchemNet) to semantically represent knowledge and develop an automatic indexing tool for Arabic documents. Then we use this resource to filter documents in order to respond to the user requests. Thus, meaningful information could be found with SchemNet ontology rather than with AWN such as a word scheme and its meaning according to the syntactic form. Furthermore, we found that this methodology is interesting to simulate the human ability to calculate the semantic similarity between the sentences of a document. This can be useful in finding relevant documents that respond to user requests. For the indexing method, we have divided each document into sentences and gave them a number for coding and creating a relationship between the index and the documents. To accomplish our objective, we used the SchemNet ontology and we had to integrate and use some tools such as FARASA [1] to apply NLP techniques.

Although the indexing process is based on the stemming phase, the current available solutions have proven that this step consumes a lot of time when processing a large volume of data. To the best of our knowledge, there are no works addressing this problem and especially through the use of agents to improve the indexing process of Arabic documents. Our objective is indexing Arabic documents based on the multi-agent system to improve the indexing process on the term of time processing. To ensure a reactive text processing that deals with NLP applications, with the agent paradigm, we can add an enhancement to solve this problem through its characteristics such as reactive, individuality, selfcontrol, autonomy, flexible, and communication [26]. The MAS is responsible for the management of the NLP process, indexing process, and filtering process.

The rest of this paper is organized as follows: Section 2 discusses the related work in addition to the background information about Arabic language. Section 3 illustrates the proposed system. Section 4 describes the experiments performed to evaluate the proposed methodology and reports the results. Section 5 discusses and justifies the analysis results. Finally, Section 6 summarizes the 
conclusions and discusses some future directives.

\section{Related Work}

In this section, we are only focusing on works that address the problem of processing and indexing Arabic documents. In the literature, a significant number of work has been conducted on the indexation of Arabic documents. Based on [18], there are three types of approaches: linguistic approaches, Numerical approaches, and hybrid approaches. Compared to other languages, Arabic is very rich in term of vocabulary both in written and spoken form. According to [34], the Lisan El-Arab dictionary which is developed in the 13th century contains more than 80,000 words, while in English, Samuel Johnson's dictionary, which is considered one of the first English dictionaries, developed in the 18th century, contains 42,000 words.

In the literature, many significant works have been conducted on the automatic processing of the Arabic language. These works are varied depending on the objective of the linguistic analysis of the linguistic phenomenon to be studied. The linguistic analysis aims to decompose the linguistic phenomenon into its main components and to use sophisticated and intelligent tools and methods based on information and communication technologies, which are based on the linguistic level of the language phenomenon to be analysed. The objectives of linguistic analysis are numerous with multiple linguistic levels (see Table 1). For example, the analysis of the phenomenon that belongs to the morphological level, is different from the analysis of the phenomenon that belongs to one of the other linguistic levels, such as the semantic and syntactic levels. According to [48], the morphological analysis gives the Arabic language a mathematical characteristic compatible with the requirements of different programming languages, which is very interesting for researchers and linguists in Arabic word processing.

The most important linguistic applications currently required are information retrieval, question/answer, translation, etc. This is the result of the significant increase in the volume of documents being exchanged and shared in the current Web. Now, it has become necessary to find new intelligent tools and algorithms that allow these documents to be processed quickly and accurately to satisfy the requirements of users.

During the last years, many researches about Arabic text processing have been done by introducing the semantic aspect, which made contents intelligently processed and used by machines. In this paper, we tried to cover some essential features of works that treat Arabic language. Based on our observation versus literature (see Table 2), there are several criteria that characterize the different works which study the Arabic language. These criteria are the work objective, the dataset used, the evaluation metrics and the results obtained, etc.

Today, researches focus on the development of a semantic approach that aims to search with concepts rather than words. Semantic indexing attempts to help the searching process to provide meaning to the searching results according to the context of the document. In this case, the most important element is the ontology, which is considered the backbone of the Semantic Web [54]. Studying the Arabic language gained much interest but only few studies focused on developing Arabic ontologybased tools. They also showed that the expressive power and the complexity of the morphological analysis of the Arabic language make it very difficult to build a strong and complete ontology for various applications [10].

In this context, many Arabic ontologies are created to present information in various domains and to facilitate the interchange of different kind of information between web's users. Each domain of knowledge is based on a certain conceptualization: objects, concepts, and other entities that are assumed to exist in some areas of interest and the relationships existing among them [32].

In [36], the authors identified a set of concepts for every Arabic word, and defined the semantic relations between these concepts. They built the top levels of the Arabic Ontology tree, which represent the most abstract concepts in Arabic with philosophical and logical relationships. While the work in [34] proposed a Bilingual Arabic-English Ontology; that regrouped Arabic words with a number of their associative relations such as synonym, ant

\begin{tabular}{|c|c|c|c|c|c|}
\hline Level in Arabic & Level in Arabic & \multicolumn{4}{|c|}{ NLPApplications } \\
\hline المستوَى الصرفي & Morpological level & $\begin{array}{c}\text { Text Stemming } \\
\text { تجذير النص }\end{array}$ & $\begin{array}{l}\text { Part-Of-Speech } \\
\text { أقشَام المذام, }\end{array}$ & $\begin{array}{c}\text { Search Engines } \\
\text { كركات البحث }\end{array}$ & $\begin{array}{c}\text { Morpological Analysis } \\
\text { التحليل الصرفى }\end{array}$ \\
\hline المتؤى النحوي & $\mathrm{Sy}_{\mathrm{y}}$ & $\begin{array}{c}\text { Text Analysis } \\
\text { تحليل نص }\end{array}$ & $\begin{array}{l}\text { Text Stemming } \\
\text { تشكيل نص }\end{array}$ & $\begin{array}{l}\text { Text Eaarab } \\
\text { إعراب الص }\end{array}$ & تصنيف نص \\
\hline الممتوَى الدلاًلي & Semantic level & $\begin{array}{c}\text { Indexing mechanism } \\
\text { الفهرسة الآلية }\end{array}$ & \begin{tabular}{|c|} 
Automatic Diacritization \\
التلخيص الآلى
\end{tabular} & $\begin{array}{c}\text { Automatic Translation } \\
\text { الترجمة الآلية }\end{array}$ & $\begin{array}{c}\text { Questions/Answering } \\
\text { أسئلة/جواب/جو }\end{array}$ \\
\hline المستوَى الصوتي & Phone & $\mid$\begin{tabular}{|c|} 
Arabic speech recognition \\
التعرف الآلي للصوت
\end{tabular} & $\begin{array}{l}\text { Text-To-Speech } \\
\text { تحويل الص إلى صوت }\end{array}$ & $\begin{array}{l}\text { Audio Indexer } \\
\text { فرسة الصوت }\end{array}$ & $\begin{array}{c}\text { Spęaker Rëcognition } \\
\text { التعرف على التُحدث }\end{array}$ \\
\hline
\end{tabular}

Table 1. Main NLP Applications according to the linguistic levels of the Arabic language 
onym, hypernym, hyponym, meronym, and holonym in an Arabic ontology called Azhary. On the other hand, the authors of in [14] created a specific domain of Arabic Ontology that treats algorithms for the purpose of information retrieval.

To the best of our knowledge, there are no studies that have treated the associations between the patterns (الأوزَان), the words and the meaning in the process of building the Arabic ontology or other NLP applications. Despite the increasing demand and interest in the use of patterns for text analysis and semantic research, there is very limited research studying it.

The existing Arabic ontologies can be regrouped into two domains depending on the information they treat: Islamic domain and Non-Islamic domain [16, 11].

For the Islamic domain, several researches have presented an important aspect of the representation and implementation of Arabic Islamic knowledge. Since the ontology is currently the most widely used element on the Semantic Web, we have found that the most recent works have focused on developing Arabic ontologies on some themes or domains related to Islamic field in order to share a common understanding of Islamic information among Muslims and also for non-Muslims. These researches were interested mainly on developing an Arabic ontology for Holy Quran [55] and Holy Hadith, etc. The Arabic Quran is the most famous book of Islam, covering many themes and domains over the world. Several researches have been done to build an ontology to be used it in the searching process or the information retrieval for the Holy Quran such as [42], [60], [46], [51]. Moreover, the paper [59] illustrates a learning ontology based on an hybrid method that combines lexico-syntactic patterns and association rules for English translation of the meaning of the Quran text.

Non-Islamic domain: The most recent Arabic ontology works on Semantic Web can be classified into two categories: The first one, works aimed at building a tool or developing a method for improving several tasks such as : information retrieval [16], translation between languages [15], Educational Applications [40], improving question answering systems [46], [53], morphology Analysis [34], text summarization [17], text annotation [9], and developing Arabic Semantic Search Engine [45].

The majority of those previous works have developed a domain ontology field that permits users to share electronic documents in different kinds of knowledge with minimum conceptual and terminological confusion. The second category of works have witnessed an increasing concern for constructing Arabic Ontology, which is a hard task [50]and can be done either manually, automatically or semi-automatically depending on the researcher's objective and the researching conditions [58]. The expressive power of the Arabic language makes it difficult to extract ontological relations automatically [10]. Therefore, the majority of the constructed Arabic Ontologies are done manually or semi-automatically today because of the complexity of the ontology construction that still needs human intervention and depends on dictionaries or other resources. Today, WordNet (AWN) developed by [22] is the most known resource for Arabic language that represents semantic relations between Synsets (groups of synonyms). However, it is still unsatisfactory to cover semantically all domains existing in this language. The [21] create a semi-automatic ontology from Arabic texts based a linguistic expert and the "Arabic verbs" of a contemporary monolingual dictionary (معجَم الغَني) in the form of a lexical database. they use Markov clustering algorithm to detect similar verbs and to identify all the synonyms of a given verbal entry. Furthermore, some works adopted for indexing documents are based on re-using existing linguistic ontologies, such as AWN [3]. Similarly, in [20], the authors propose a model based on mathematics and ontologies, which formalizes the morphological knowledge of Arabic language verbs and their derivatives.

Another work was done to build an Arabic VerbNet (AVN) ([38]), which uses the Levin's classes for the automatic extension of AVN via sibling classes [44]. The current version has 202 classes populating 4707 verbs and 834 frames. Every class is a hierarchical structure providing syntactic and semantic information about verbs and filtering them to subclasses. However, despite the importance of the Arabic verbs, very few publications are available in literature that address the impact of the classification of Arabic verbs in Information Retrieval. The most interesting approach to this issue has been proposed by ([47]). In this work, they construct a new Arabic ontology combining the contents of Arabic AWN and AVN. They have also adopted the Conceptual Graphs representation to present the AVN frames that allow a better semantic representation and matching in intelligent Arabic QA systems. However, this approach may not be practical to express all situations of CGs of each verb.

Moreover, we conclude that the current Arabic ontologies have been developed are for objective to improve a specific task in particular domain of interest which are not satisfactory for various tasks such as information retrieval, Question Answering, text summarization, text annotation, and text translation together. The contribution of the ontologies with Arabic language is very interesting but it requires an important effort to develop a complete lexical resource in a large domain, to be used in various tasks. These surveys justify the requirement to develop Arabic ontology and contribute to the development of semantic web tools and applications. Our work fills a gap in the context of the semantic web and focuses on the tasks of facilitating indexing documents and Information Retrieval.

\section{Background}

In this work, we have built a new ontology based on two 


\begin{tabular}{|c|c|c|c|c|c|c|c|c|c|}
\hline Work & Year & Objective & Domain & Method & Technique & Dataset & $\begin{array}{c}\text { Evaluation } \\
\text { Metrics }\end{array}$ & Features & Results \\
\hline$[18]$ & 2014 & $\begin{array}{l}\text { Arabic text } \\
\text { preprocessing } \\
\text { tools. }\end{array}$ & Islamic & $\begin{array}{l}\text { Maxent } \\
\text { machine } \\
\text { learning } \\
\text { package }\end{array}$ & $\begin{array}{l}\text { Java-based } \\
\text { toolkit }\end{array}$ & $\begin{array}{l}\text { Holy Hadith } \\
\text { (Sayings of } \\
\text { the Prophet } \\
\text { Mohammed) }\end{array}$ & I & $\begin{array}{l}\text { Modules for } \\
\text { processing } \\
\text { Arabic text }\end{array}$ & $\begin{array}{l}\text { Arabic } \\
\text { ontology }\end{array}$ \\
\hline [13] & 2016 & $\begin{array}{l}\text { Processing } \\
\text { toolkit for } \\
\text { Arabic text }\end{array}$ & / & $\begin{array}{l}\text { SVM-rank } \\
\text { using linear } \\
\text { kernels }\end{array}$ & $\begin{array}{l}\text { Likelihoods } \\
\text { of stems }\end{array}$ & / & $\begin{array}{l}\text { Accuracy and } \\
\text { efficiency }\end{array}$ & $\begin{array}{l}\text { Modules for } \\
\text { processing } \\
\text { Arabic text }\end{array}$ & $\begin{array}{l}\text { Web Site, } \\
\text { free online }\end{array}$ \\
\hline [19] & 2016 & $\begin{array}{l}\text { Word } \\
\text { stemming }\end{array}$ & $\begin{array}{l}\text { Non- } \\
\text { Islamic }\end{array}$ & $\begin{array}{l}\text { Maximal } \\
\text { Marginal } \\
\text { Relevance } \\
\text { (MMR) } \\
\text { method } \\
\end{array}$ & $\begin{array}{l}\text { Cosine } \\
\text { similarity } \\
\text { measure }\end{array}$ & $\begin{array}{l}\text { Arabic } \\
\text { articles with } \\
42 \text { articles }\end{array}$ & $\begin{array}{l}\text { Precision, } \\
\text { Recall and } \\
\text { F- measure }\end{array}$ & $\begin{array}{l}\text { Arabic text } \\
\text { summarization }\end{array}$ & / \\
\hline$[20]$ & 2017 & $\begin{array}{l}\text { Arabic } \\
\text { stemming }\end{array}$ & Islamic & $\begin{array}{l}\text { Arabic } \\
\text { Natural } \\
\text { Language } \\
\text { Processing } \\
\text { (ANLP) }\end{array}$ & $\begin{array}{l}\text { Stems } \\
\text { lexicon }\end{array}$ & $\begin{array}{l}\text { Quranic Arabic } \\
\text { Corpus with } \\
18,350 \text { uniqu } \\
\text { words }\end{array}$ & $\begin{array}{l}\text { Accuracy, } \\
\text { number of } \\
\text { Words Per } \\
\text { Conflation } \\
\text { Class (WCC) } \\
\text { and Gs-score } \\
\text { (for Global } \\
\text { Ste-mming } \\
\text { Score) }\end{array}$ & $\begin{array}{l}\text { SAFAR } \\
\text { framework } \\
\text { resource API }\end{array}$ & $\begin{array}{l}\text { Accuracy } \\
\text { with } \\
33.7 \%\end{array}$ \\
\hline [21] & 2019 & $\begin{array}{l}\text { Hadoop } \\
\text { implementation } \\
\text { based platform } \\
\text { for stemming } \\
\text { heavy document } \\
\text { of arabic } \\
\text { words }\end{array}$ & Islamic & $\begin{array}{l}\text { Khoja } \\
\text { algorithm } \\
\text { and Map } \\
\text { reduce } \\
\text { model }\end{array}$ & $\begin{array}{l}\text { Parallel } \\
\text { Stemming } \\
\text { Algorithm } \\
\text { (PSA) }\end{array}$ & $\begin{array}{l}\text { Heavy } \\
\text { document } \\
\text { of Quan text } \\
\text { (with } 165248 \\
\text { words) }\end{array}$ & $\begin{array}{l}\text { Execution } \\
\text { time } \\
\text { evoluation }\end{array}$ & $\begin{array}{l}\text { Arabic } \\
\text { information } \\
\text { retrieval }\end{array}$ & $\begin{array}{l}2.121 \\
\text { seconds }\end{array}$ \\
\hline [22] & 2015 & $\begin{array}{l}\text { Automatic } \\
\text { summarization }\end{array}$ & $\begin{array}{l}\text { Non- } \\
\text { Islamic }\end{array}$ & $\begin{array}{l}\text { Five } \\
\text { algorithms } \\
\text { discourse } \\
\text { segmentation, } \\
\text { coordinate/ } \\
\text { subordinate } \\
\text { relations, } \\
\text { Complex } \\
\text { Discourse } \\
\text { Units (CDUs) } \\
\text { and discourse } \\
\text { Structure }\end{array}$ & $\begin{array}{l}\text { SDRT } \\
\text { framework with } \\
\text { embedded seg- } \\
\text { ments and the } \\
\text { CDU notion }\end{array}$ & $\begin{array}{l}\text { Two different } \\
\text { corpora: } \\
\text { ADTB } \\
\text { and AD-RST }\end{array}$ & $\begin{array}{l}\text { Precision, } \\
\text { recall and F- } \\
\text { measure and } \\
\text { ROUGH, } \\
\text { Recall- } \\
\text { Oriented } \\
\text { Understudy } \\
\text { for Gisting }\end{array}$ & $\begin{array}{l}\text { An automatic } \\
\text { Arabic text } \\
\text { summarization } \\
\text { tool }\end{array}$ & $\begin{array}{l}\text { F-measure }= \\
0.437 \text { for } \\
\text { ADTB and } \\
\text { F-measure }= \\
0.411 \text { for } \\
\text { AD-RST }\end{array}$ \\
\hline [23] & 2014 & $\begin{array}{l}\text { Keyphrases } \\
\text { Extraction }\end{array}$ & $\begin{array}{l}\text { Non- } \\
\text { Islamic }\end{array}$ & $\begin{array}{l}\text { Linear logistic } \\
\text { regression, } \\
\text { linear } \\
\text { discriminant } \\
\text { analysis, } \\
\text { and support } \\
\text { vector }\end{array}$ & $\begin{array}{l}\text { Hybrid: } \\
\text { statistical } \\
\text { features with } \\
\text { machine } \\
\text { learning } \\
\text { methods }\end{array}$ & $\begin{array}{l}\text { Arabic } \\
\text { documents }\end{array}$ & $\begin{array}{l}\text { Precision, } \\
\text { Recall and } \\
\text { F-score and } \\
\text { TF-IDF }\end{array}$ & $\begin{array}{l}\text { Automatic } \\
\text { keypharse } \\
\text { extraction }\end{array}$ & $\begin{array}{l}\text { SVM with } \\
\text { FI-Measure } \\
\text { of } 88.31 \%\end{array}$ \\
\hline [24] & 2013 & $\begin{array}{l}\text { Knowledge } \\
\text { Extraction } \\
\text { Syatem for } \\
\text { Arabic }\end{array}$ & $\begin{array}{l}\text { Non- } \\
\text { Islamic }\end{array}$ & $\begin{array}{l}\text { Deep morpho- } \\
\text { syntactic } \\
\text { analysis and } \\
\text { domain } \\
\text { ontology }\end{array}$ & $\begin{array}{l}\text { Linguistic } \\
\text { approach }\end{array}$ & $\begin{array}{l}\text { Press article } \\
\text { Aljazeera and } \\
\text { ANER Corpus } \\
\text { with } 150000 \\
\text { words }\end{array}$ & Precision & $\begin{array}{l}\text { Dependency } \\
\text { relations, verb } \\
\text { tenses and } \\
\text { passive/ } \\
\text { active forms }\end{array}$ & $\begin{array}{l}\text { Precision }= \\
0.998 \%\end{array}$ \\
\hline$[25]$ & 2012 & $\begin{array}{l}\text { Automatic } \\
\text { Arabic docu- } \\
\text { ment } \\
\text { indexing }\end{array}$ & $\begin{array}{l}\text { Non- } \\
\text { Islamic }\end{array}$ & Inverted index & $\begin{array}{l}\text { Linguistic } \\
\text { approach }\end{array}$ & $\begin{array}{l}\text { Arabic } \\
\text { Websites (50 } \\
\text { documents) }\end{array}$ & $\begin{array}{l}\text { Precision and } \\
\text { Recall }\end{array}$ & $\begin{array}{l}\text { Automatic } \\
\text { Document } \\
\text { Indexing }\end{array}$ & $\begin{array}{l}\text { Precision }= \\
0.998 \%\end{array}$ \\
\hline$[2]$ & 2015 & $\begin{array}{l}\text { Information } \\
\text { Retrieval } \\
\text { system }\end{array}$ & $\begin{array}{l}\text { Non- } \\
\text { Islamic }\end{array}$ & $\begin{array}{l}\text { Hybrid Index } \\
\text { frequency }\end{array}$ & $\begin{array}{l}\text { Linguistic } \\
\text { approach }\end{array}$ & $\begin{array}{l}\text { OSAC corpus } \\
\text { and } 70 \text { simple } \\
\text { queries }\end{array}$ & $\begin{array}{l}\text { Precision and } \\
\text { Recall }\end{array}$ & $\begin{array}{l}\text { Indexation of } \\
\text { Documents and } \\
\text { Queries }\end{array}$ & $\begin{array}{l}\text { Medium Aver- } \\
\text { age Precisin }= \\
0,551 .\end{array}$ \\
\hline [26] & 2016 & $\begin{array}{l}\text { Information } \\
\text { Retrieval (IR) } \\
\text { system }\end{array}$ & $\begin{array}{l}\text { Non- } \\
\text { Islamic }\end{array}$ & $\begin{array}{l}\text { Hybrid Index } \\
\text { frequency }\end{array}$ & $\begin{array}{l}\text { Hybrid Index } \\
\text { frequency }\end{array}$ & $\begin{array}{l}\text { ZAD Collec- } \\
\text { tion with } 2,730 \\
\text { documents }\end{array}$ & $\begin{array}{l}\text { Precision and } \\
\text { Recall }\end{array}$ & $\begin{array}{l}\text { Arabic } \\
\text { document } \\
\text { Indexing }\end{array}$ & $\begin{array}{l}\mathrm{N}=20 \text { and } \\
\text { Precision }= \\
0,2708\end{array}$ \\
\hline
\end{tabular}




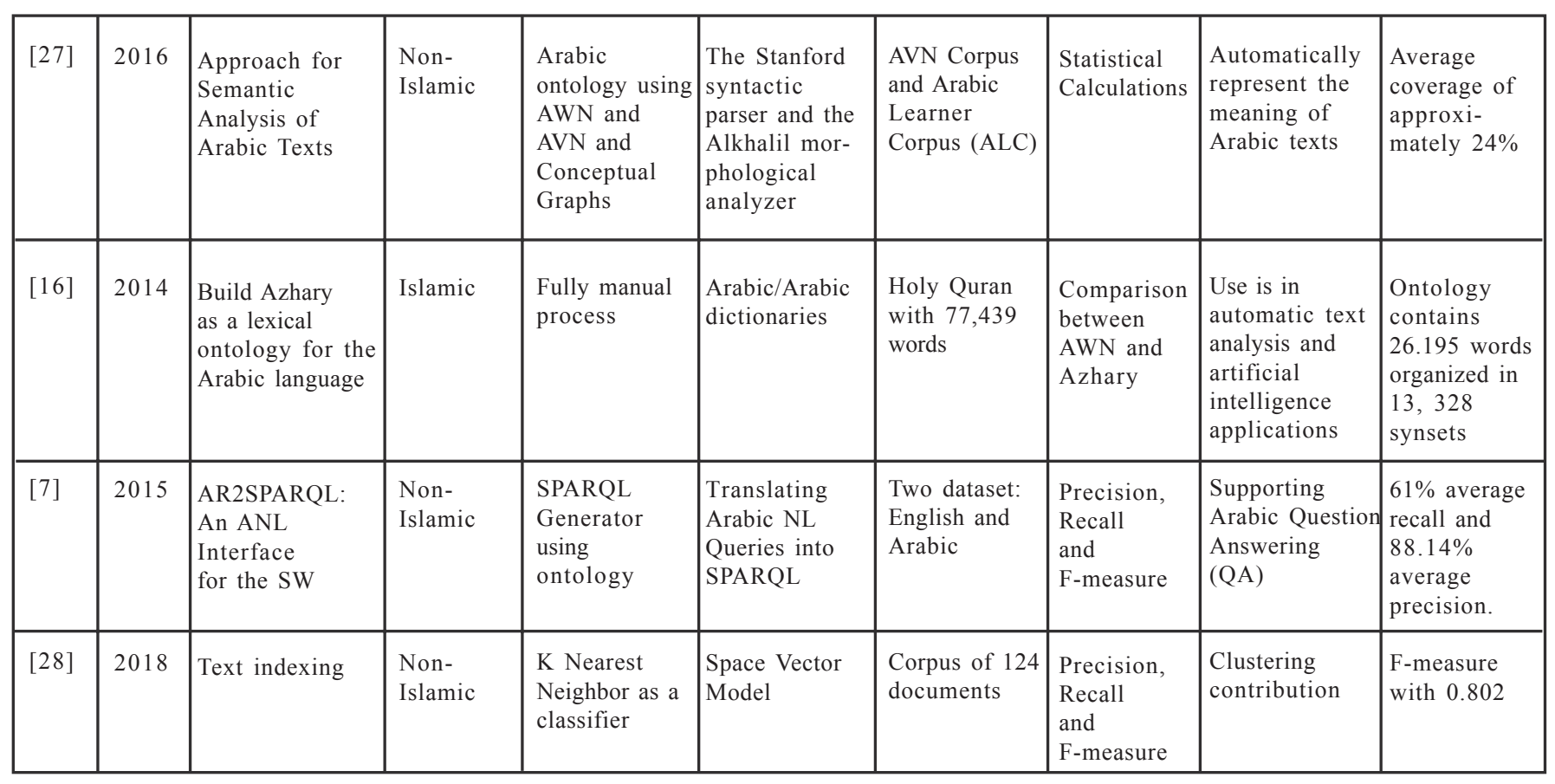

Table 2. General comparison between the existing works for NLP of Arabic documents

other sources: AWN and AVN, also we used some tools/ platforms that we briefly present in the following sub-sections.

\subsection{Arabic WordNet}

Arabic WordNet $[\mathrm{x}]$ is a lexical resource for Modern Standard Arabic (MSA), which is widely used by Internet users in the Arabic world. It is a WordNet for the Arabic language, since its creation in 2006 [24], it was extended in 2015[5] to use wordnets in multiple languages. The current version contains 9,916 Synsets, 17,785 words and 37,335 Senses. The Synsets are a set of Arabic words with their synonyms and semantic relations.

\subsection{Arabic VerbNet}

This work is a classification of a set of Arabic verbs according to the Levin method. It contains 336 classes, 7744 verbs and 1399 frames in which information is provided on the verb root, verbal form, participle, thematic roles, and frames, syntactic, and semantic descriptions of verbs. Each class is a hierarchical structure that provides grammatical and semantic information about verbs and forwards them to sub-categories [39].

\subsection{Farasa : Advanced tools for Arabic}

FARASA [1] (which means "insight" in Arabic), is a fast and accurate text processing toolkit for automated for processing of Arabic text. It consists of several parts where it helps to find the roots of words and determine the grammatical and morphological function, as well as the formation and analysis of the text. Its objective is to automatically translate texts and retrieve information accurately and quickly according to the user's needs. In our work, we use Farasa to PoS tagger.

\subsection{Khoja Stemmer}

Stemming algorithms are widely used in many NLP applications such as information retrieval systems, indexing systems, text translation, text summarization, etc. The purpose of Arabic stammering is to extract the stems or roots of the different Arabic words. As many stemming algorithms have been built for the Arabic language, we used the Khoja stemmer since it is one of the best known and most used of the Arab stemmers [43]. It is based on predefined root lists and patterns. This data is stored in text files that are used in morphological analysis to find the root of a given Arabic word. We note that we use these files to create our ontology which called SchemNet.

\section{Construction of SchemNet Ontology}

For the indexing of Arabic documents, we have built a new ontology based on Arabic patterns and their meaning. For this purpose and in order to design and build this ontology, many studies have proposed many methods and methodologies, in which we try to apply the method mentioned in the work [56], which is based on a set of fundamental steps as follow:

- Step 1: Define the objective of creating or building an ontology. In our case, we build the ontology for indexing Arabic documents using patterns and theirs meaning.

- Step 2: Construct the methodology after determining the different parts of classes and individuals and the relationships between them.

- Step 3: Use the ontology to check the response to the objectives proposed above. 


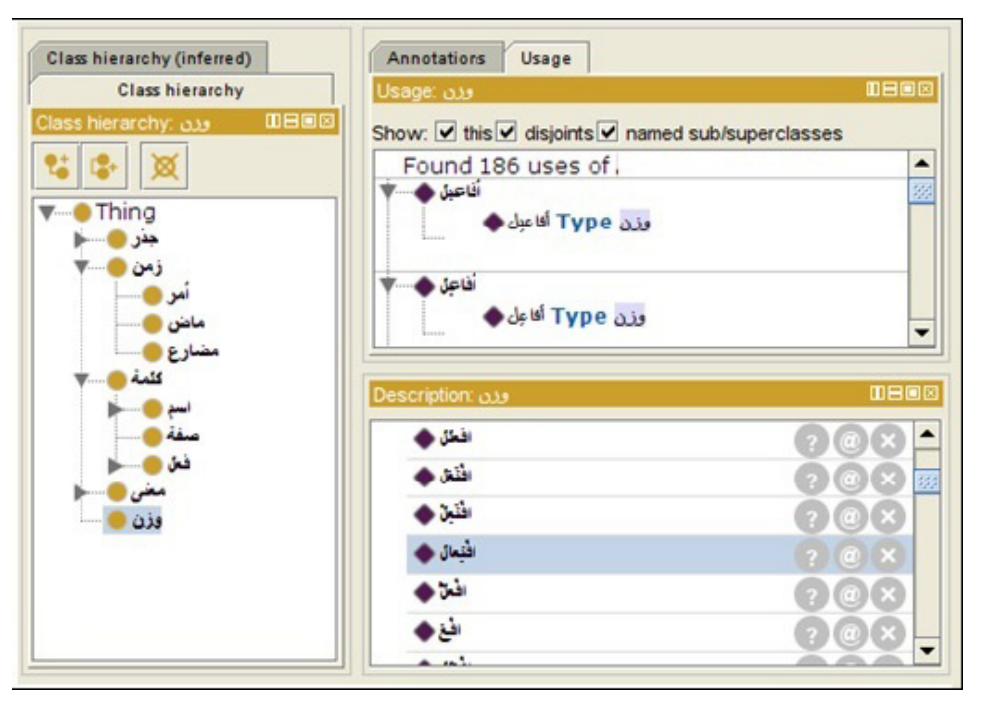

Figure 1. Part of our Arabic ontology (SchemNet)

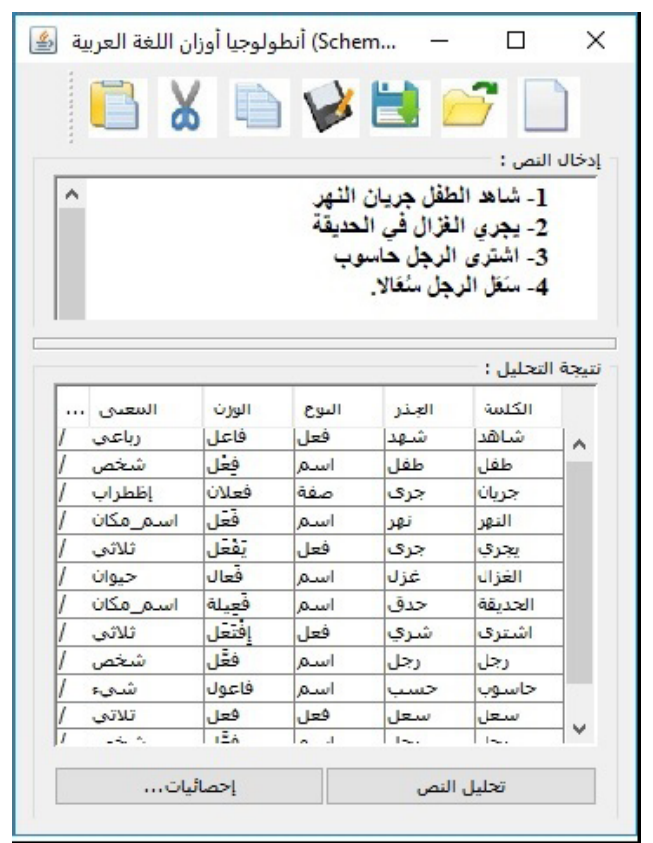

Figure 2. Graphical interface of an example of an analysis of a set of Arabic sentences
The ontological structure of SchemNet contains five classes: (Root), (time), (word), (meaning) and (Pattern)(see the Figure 1). The Root is the main class, each root has several subclasses. A Sense class is a meaning of the word according to its pattern. A pattern class contains all Arabic schemes with diacritics. In this ontology, we use several relationships between words and patterns, and the meaning of these patterns, examples of relation type are: is_type_of, has_pattern, has_synonym.

Figure 1 represents an overview of SchemNet Ontology developed for indexing Arabic documents. Since, "85\% of Arabic words are derived from trilateral roots" [34], we found that is interesting to build Ontology based on the roots, which certainly results to, the existence of concepts with different meanings sharing the same root and consequently sharing the same class [11]. Moreover, We know that there are words in Arabic with no roots but we handle these words by adding a class called pattern. We classify these words and others by using both the root and the pattern and consequently adding their meaning depending to their scheme. We use the AWN and the AVN in the process of building the SchemNet ontology.

Figure 2 is an example of an analysis of a set of sentences in Arabic. These results are obtained after semantic indexing using schemNet. Compared to the AWN, we found that our ontology gives additional information such as pattern with sense. These information can be very helpful to calculate the semantic similarity between sentences.

\section{The Proposed System}

In this paper, the aim is to propose a multi-agent and ontology-based approach for indexing and filtering Ara bic documents. We propose a new approach to index Arabic documents based on SchemNet ontology, which is manually constructed with the combination of AWN and AVN. The proposed system in Figure 3 is composed of five layers, as follow:

\subsection{Lexical Layer}

This layer includes the Arabic text analysis. It receives data from Indexing layer or from User Layer to be checked and normalized. This operation aims to process the text and extract terms after removing stop-words. This layer contains many agents that cooperate to achieve the main goal, which is text preprocessing (Tokenization, normalization, and stop-words removing). These agents are created by a supervised agent, which is responsible for receiving requests and organizing treatment.

\subsection{Syntactic Layer}

This is the most difficult layer, it consists of stemming Arabic documents or user queries. It is also responsible to extract PoS of each word in the text. These operations consume a lot of time. To resolve this problem, we designed a system based on agents in order to take advantages of their characteristics such as: autonomy and reactivity. This layer contains a master agent, which its role is to create stemmer agent for each document or query, and this agent is responsible for extracting the required information (stem and Pos) of each word. These operations are realized using Farasa and khoja stemmer.

\subsection{Semantic Layer}

This layer is based on ontology to extend or create indexes of the documents and queries. We used a semantic resource that we built for indexing Arabic documents. The process of the indexing is done by extract- 


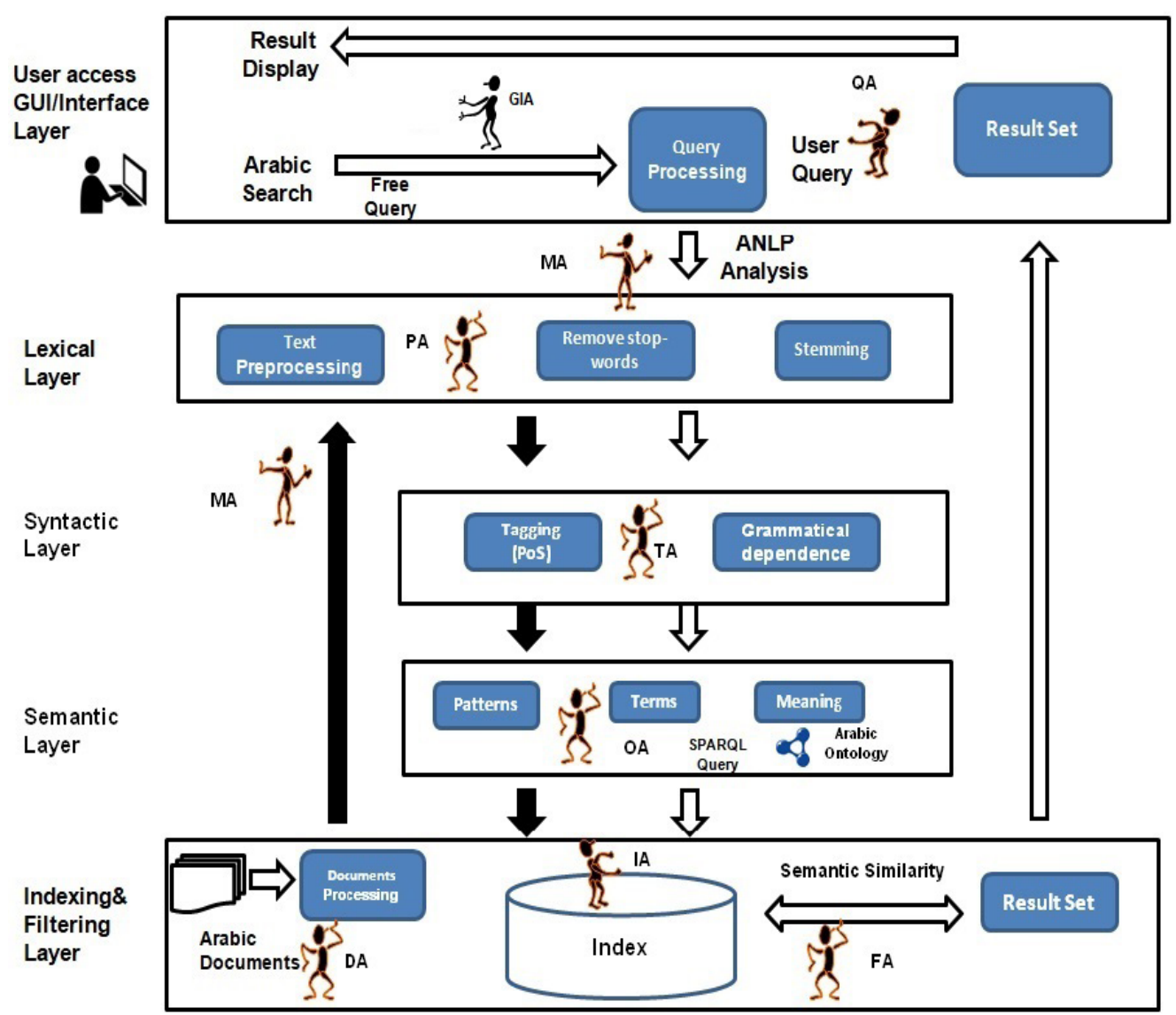

Figure 3. Architecture of the proposed system

ing semantic information such as terms, concepts and relations between these concepts. These information are related semantically and extracted from the ontology as shown in Algorithm 1.

In this layer, an ontology agent has been assigned to deal with all operations that concern the Arabic ontology (SchemNet). This agent interacts with indexing agent to achieve their goals.

\subsection{Indexing Layer}

This is the most important layer in our work. It creates an index for each document and for user's query. In our approach, we create an index for each sentence in document $D_{i}\left(S_{1}, S_{2}, \ldots, S_{n}\right)$. The objective is to select the appropriate sentences that will be similar to user's query. In this layer, it decides whether a document will be selected as relevant or not. The process of indexing documents is presented in algorithm 1.

The equation 1 permits us to verify if the sentence $S_{i}$ of document $D_{j}$ is similar to sentence of query $Q_{k}$ or not. In order to extract the relevant document according to the user's query, we measure the semantic similarity between sentences. Each sentence $S_{i}\left(w_{1}, w_{2}, \ldots, w_{n}\right)$ is represented by a vector of integer $T S_{i}\left(v_{1}, v_{2}, \ldots, v_{i}\right)$. We have used the equation 1 to measure the similarity between two sen tences.

$$
\operatorname{Sim}=\left(\frac{\sum T S_{1}+\sum T S_{2}}{t_{1}+t_{2}}\right) / 2
$$

Example: This example illustrates the processes developed for computing the similarity between two candidate sentences in our system. We have two sentences: S1 and $\mathrm{S} 2$ as follow:

S1 = "يلبس الرجل معطفًا أسود" (The man is wearing a black coat).

S2 = "يرتدي الطفل قميصَا قصيرًا" (The child is wearing a short shirt).

Several operations are applied on both sentences $\left(S_{1}\right.$ and $S_{2}$ ) as mentioned previously. We obtained the results reported in Table 3 for sentence $S_{1}$ and Table 4 for sentence $S_{2}$.

The similarity between $S 1$ and $S 2$ is calculated by apply ing the equation 1 :

$\operatorname{Sim}\left(S_{1}, S_{2}\right)=\left(\frac{\left(\sum T S_{1}+\sum T S_{2}\right.}{t_{1}+t_{2}}\right) / 2=\left(\frac{3+3}{4+4}\right) / 2=0.75$ 


\subsection{GUI/Interface Layer}

This layer represents the mediator between human user and the machine (system). We offer to the users a graphical interface that can help users to enter a free query for searching information. Moreover, the main concern of this phase is to capture the query of the user and display the obtained results with high accuracy and short time. In this layer, an interface agent has been assigned to interact easily through the graphical interface. It can guide and control the user.

\section{Multi-Agent System}

In our approach, the proposed system is based on a multiagent architecture of several co-operating agents, having adaptive capabilities to environmental change, and supporting retrieval of the relevant documents using ontology. These agents can (a) communicate with the others to delegate tasks, (b) make elementary reasoning and decisions, and help to choose between several documents [25]. MAS are used to abstract, to model and to implement complex systems. [26] defined MAS as a compendium of different agents with their own problem solving capabilities and goals. The conceptual design of the proposed system is based on the interaction between nine agents as it is illustrated in Figure 3. MAS has the responsibility to establish two important scenarios for the system: the indexing of Arabic documents and the filtering process. Each agent has a set of modules, which are necessary to accomplish its task. The communication module between agents is a common module with all agents. It allows each agent to communicate with other agents.

The implementation of the MAS has been made easier by the use of a pre-existing software framework for the development of agent applications called JADE [35]. Our system is implemented with JADE, an open source MAS platform that complies with FIPA [27] specifications, which provides debugging tools to generate message sequence diagrams.

\subsection{Functionalities Description of Agents}

The conceptual design of the proposal is based on the interaction between nine agents.

\section{Manager Agent}

This agent is important in our system. It acts as a coordinator between several agents (QA, DA) as shown in Fig ure 4. It performs the following functions:

- Ensuring effective communication between the different agents;

- Generating the processing and tagging agents to extract the lexical and syntactic units from documents and user queries;

- For a set of documents, this agent can generate a set of agents (eg. PA, TA, OA, and IA) that cooperate with each other to create the index of each document. This is for role to apply the NLP techniques on documents in parallel to minimize the processing time, which is the big problem faced by the linguistic approach.

\section{Document Agent}

The role of this agent is to detect the documents loaded by users and prepare them to be sent its to the Manager agent in order to create an index for these documents. Figure 5 represents the architecture of DA.

\section{Query Agent}

This agent acts as a mediator between the GIA and the MA. The architecture of QA is presented in Figure 6. It performs the following functions:

- Receiving the query of the user to extract the relevant documents after the filtering process.

- Checking the user's query if they are written in Arabic language.

- Sending the checked query to the manager agent (MA) to create the semantic index, which will be used in filtering process to find the relevant documents that respond to the user's query.

\section{Processing Agent}

This agent cleans documents and queries by applications of NLP techniques as a preprocessing phase (see Figure 7). It applies a set of operations as follow:

- Delete diacritics, Latin characters, special characters, and numbers.

- Normalize words by replacing letters $i, !$ and $\uparrow$ by $I$.

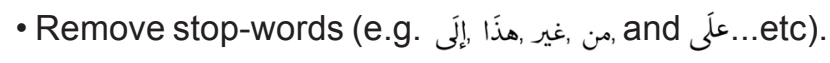

- Tokenize each sentence of document to use it in the next step.

At the end, it sends the result to the TA agent to continue the NLP process.

\section{Tagging Agent}

It aims at extracting all the PoS of each word of sentence in each document and saving them in a text files in the form of a document index. This process is the same for queries.

In the searching process, only roots which are extracted later are used to find relevant documents that meet the user's requests. The internal architecture of this agent is composed of three modules as shown in figure 8. For PoS process, we use FARASA system, which is a free software available for standard Arabic text. 
Algorithm 1: Extracting index from Arabic documents using SchemNet ontology

Input: Set_OfArabic_Documents : D, SchemNet_Ontology:Onto

Output: List_of_Index

/* an index for each sentence */

1 for each document $d_{i}$ in $D$ do

2 for each sentence $S_{j}$ in $d_{i}$ do

$3 \quad \mathrm{~S}_{j} \leftarrow \operatorname{Normalization}\left(\mathrm{S}_{j}\right)$

$4 \quad \mathrm{~S}_{j} \leftarrow$ Remove_stop_words $\left(\mathrm{S}_{j}\right)$

$5 \quad$ List_Words $\leftarrow$ Tokanization $\left(\mathrm{S}_{j}\right)$

$6 \quad$ List_Root $\leftarrow$ Find_Root $\left(\right.$ List_Words of $S_{j}$ ); List_PoS $\leftarrow$ Find_Tagging (List_Words of $S_{j}$ ); for each word $W_{k}$ in $S_{j}$ do

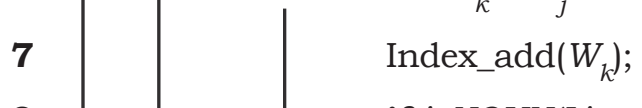

8

9

10

11

12

13

14

15

16

17

18

19

20

21

22

23

24

25

26

27

28

29

30

if isNOUN(List_PoS[k]) then

Type $\leftarrow$ Sparql_OntoT $\left(W_{k}\right.$, Onto);

Pattern $\leftarrow$ Sparq1_OntoP $\left(W_{k}\right.$, Onto $)$;

Sense $\leftarrow$ Sparq1_OntoS $\left(W_{k}\right.$, Pattern, Onto $)$;

Index_add(Type);

Index_add(Pattern);

Index_add(Sense);

end

if isAdj(List_PoS[k]) then

Syn $\leftarrow$ Sparql_OntoSY $\left(\mathrm{W}_{k}\right.$, Onto $)$;

Pattern $\leftarrow$ Sparq1_OntoP $\left(\mathrm{W}_{k}\right.$, Onto $)$;

Sense $\leftarrow$ Sparq1_OntoS( $\mathrm{W}_{k}$, Pattern,Onto);

Index_add(Syn);

Index_add(Pattern);

Index_add(Sense);

end

if isVerb(List_PoS[k]) then

Syn $\leftarrow$ Sparq1_Onto( $\mathrm{W}_{k}$, Onto);

Index_add(Syn);

end

Index_add(List_Root);

end

31 end 


\begin{tabular}{|c|c|c|c|c|c|c|c|}
\hline $\mathbf{N}$ & WORD & POS & Root & Semantic & Category & Pattern & $\mathrm{TS}_{1}$ \\
\hline 1 & يليس & V & لليس & يرتئي & Syns & يقعل & 1 \\
\hline 2 & الطنَل & NOUN & طُ طنل & شخص & Type & الفعل & 1 \\
\hline 3 & Laئ" & NOUN & (3) & لصابن & Type & فعيل & 1 \\
\hline 4 & Daقs & $\overline{\text { AGJ }}$ & قصر & طول & Type & فعيل & 0 \\
\hline
\end{tabular}

Table 3. Illustrative example of the processing of S1

\begin{tabular}{|c|c|c|c|c|c|c|c|}
\hline $\mathbf{N}$ & WORD & POS & Root & Semantic & Category & Pattern & $\mathrm{TS}_{1}$ \\
\hline 1 & يريتي & $\mathrm{V}$ & إرتيى & ليس & Syns & يقمل & 1 \\
\hline 2 & الريط & NOUN & , & ثئس & Type & الفعل & 1 \\
\hline 3 & líbew & NOUN & ع ع & لئاسن & Type & Aفسل & 1 \\
\hline 4 & أَسوة أ & AGJ & سوب & لون & Type & أُقَل & 0 \\
\hline
\end{tabular}

Table 4. Illustrative example of the processing of S2

\section{Filtering Agent}

This agent serves to filter the documents according to the query of users (see Figure 9). It receives information about the index of query and documents sent by the IA agent. Then, it calculates the semantic similarity between each sentence of the document and the query, also it sends the list of relevant documents to the QA agent (see Algorithm 2). It searches and retrieves documents matching user's queries. The calculation of the similarity is done by using the formula defined in the equation 1 .

\section{Ontology Agent}

This agent performs ontology management of Arabic content and scheme management (see its architecture in Figure 10). It extracts and saves the information received from the TA agent regarding the Arabic documents (synonym, root, meaning, and pattern, etc.). It also responds to requests sent by the indexing and updates the ontology when it is needed. Our ontology is based on Arabic patterns (الأوزَان) with their words' semantic meaning.

\section{Indexing Agent}

The role of this agent is gathering the information received from OA, which contain a list of words to be indexed or stored, then adding these information about each sentence of the document to the index. Also, maintaining the index as a list of sub-index that allows our system to calculate the semantic similarity between documents and queries from the index. Figure 11 presents the architecture of this agent.

\section{Graphical Interface Agent}

This agent allows users to interact with the system. Through this interface, users can express their requests and visualize their results. In addition, the interface agent ensures the display of all results obtained after the research process. It interacts with others agents (QA and FA) as shown in Figure 12 to meet the request of users.

\subsection{The Communication between Agents} We have two main scenarios as follows:

\section{Semantic Document Indexing (SDI)}

The message sequences diagram provided in Figure 13 illustrates the process of indexing Arabic documents and corresponds to the following textual descriptions:

1. Through the system, the DA detects the presence of a

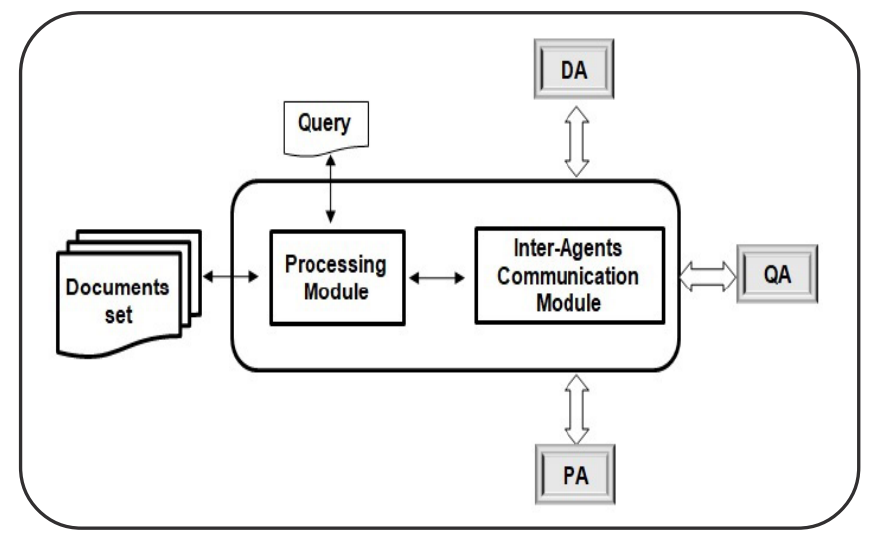

Figure 4. The architecture of Manager Agent(MA)

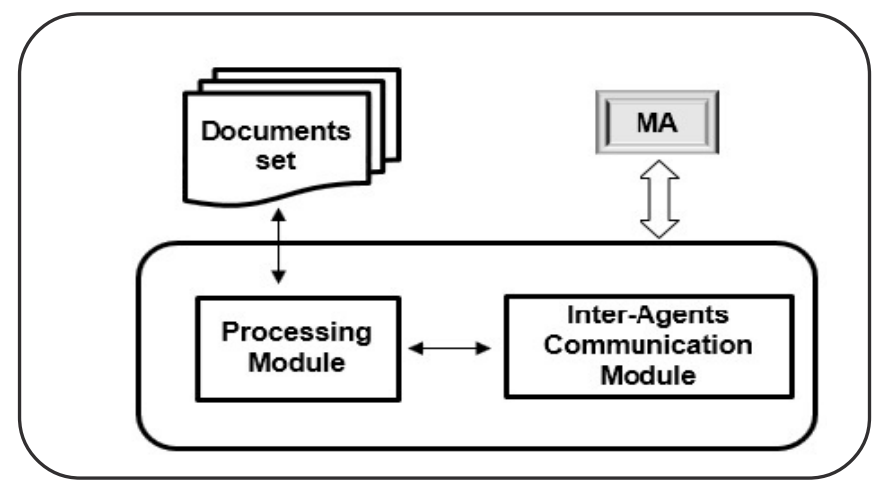

Figure 5. The architecture of Document Agent(DA) 


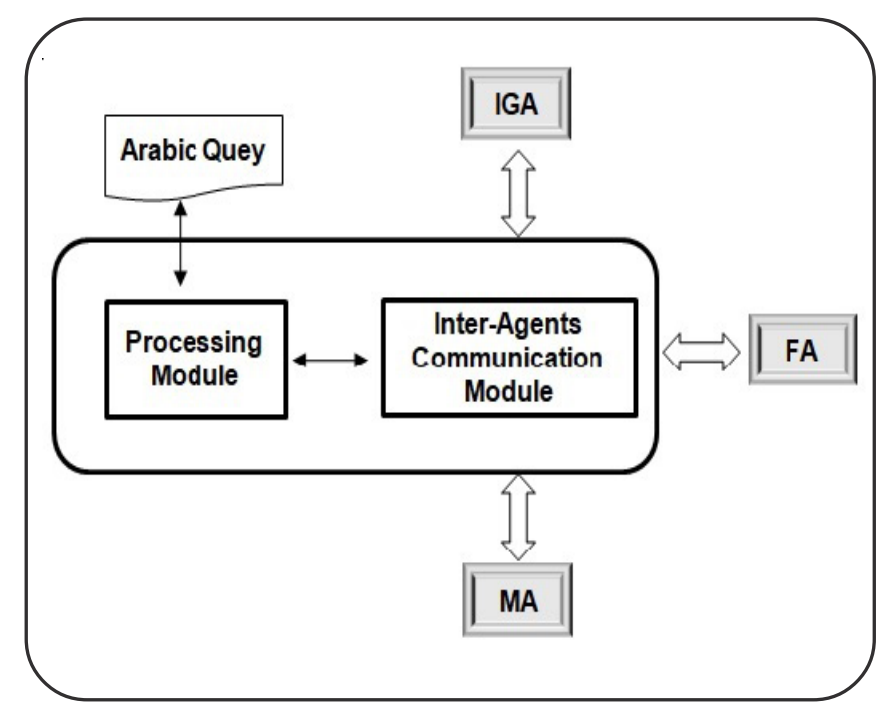

Figure 6. The architecture of Query Agent(QA)

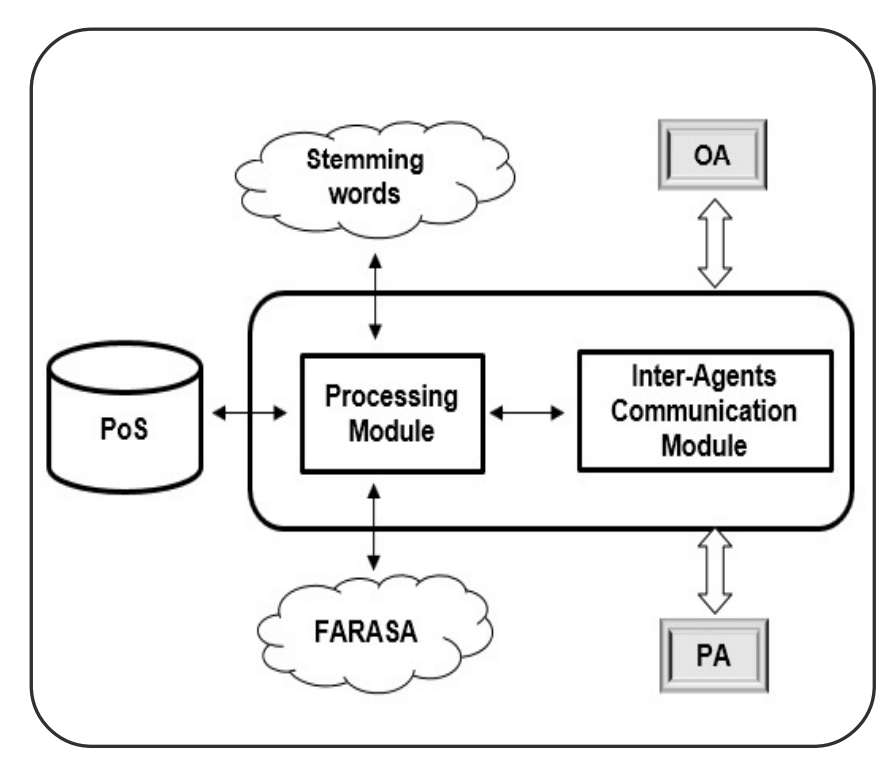

Figure 8. The architecture of Tagging Agent(TA)

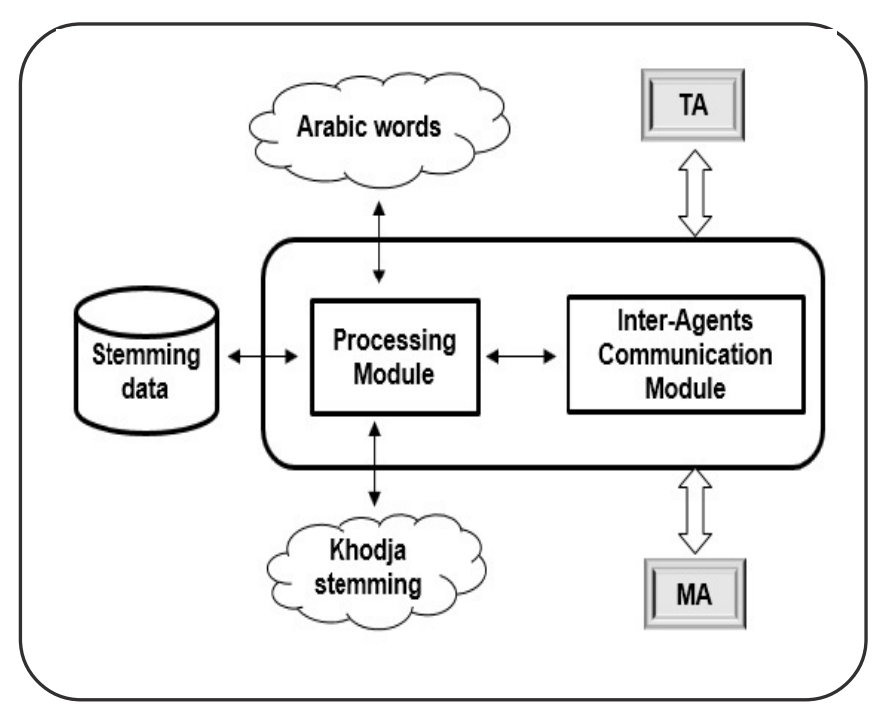

Figure 7. The architecture of Processing Agent(PA)

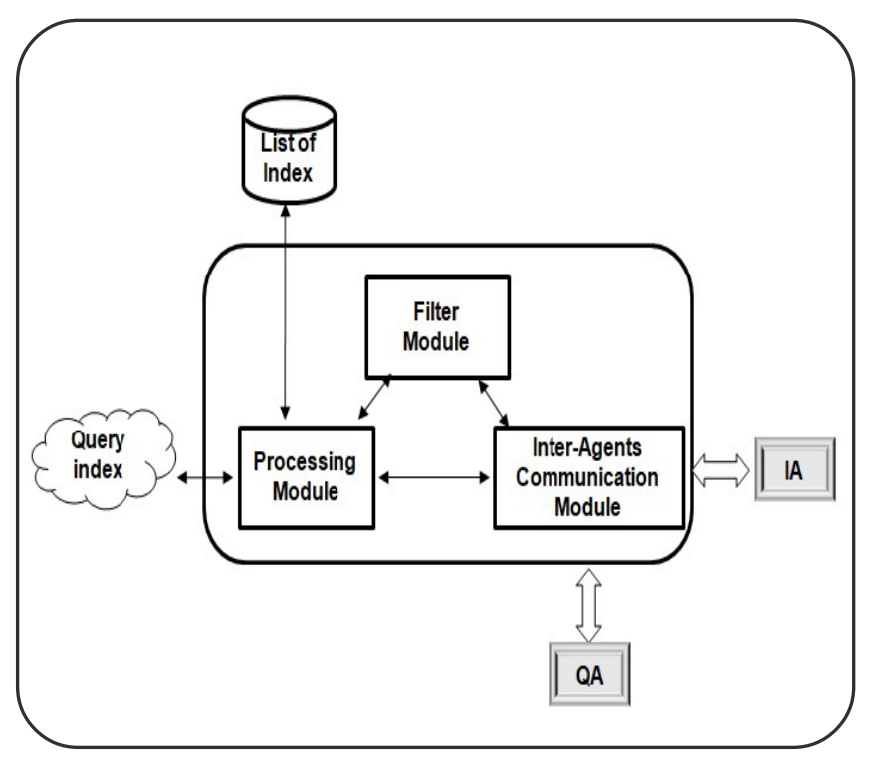

Figure 9. The architecture of Filtering Agent (FA)

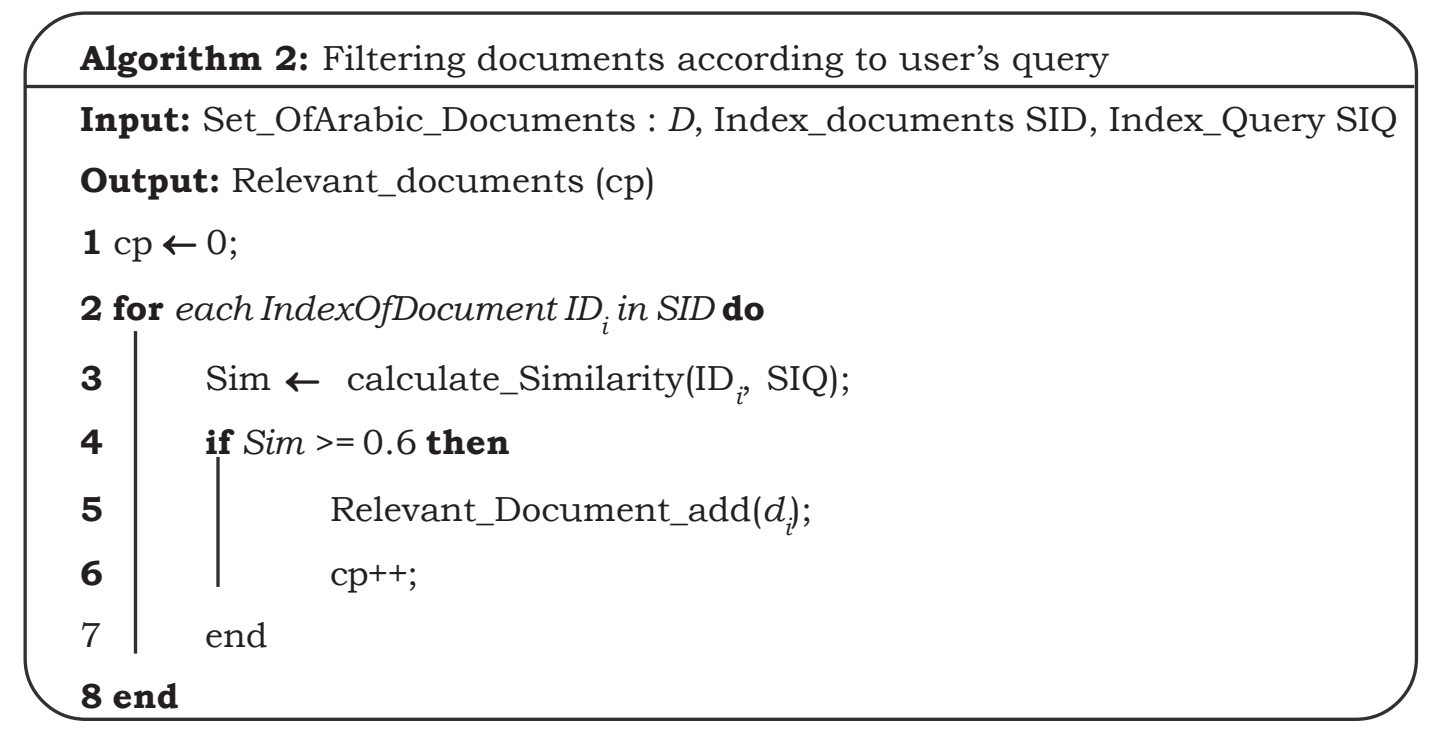




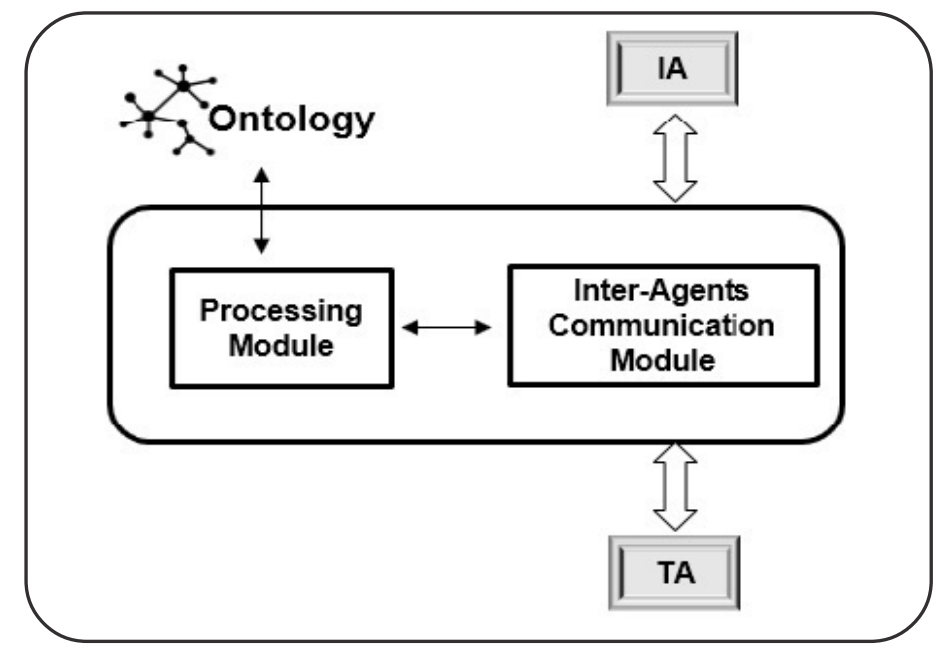

Figure 10. The architecture of Ontology Agent $(\mathrm{OA})$

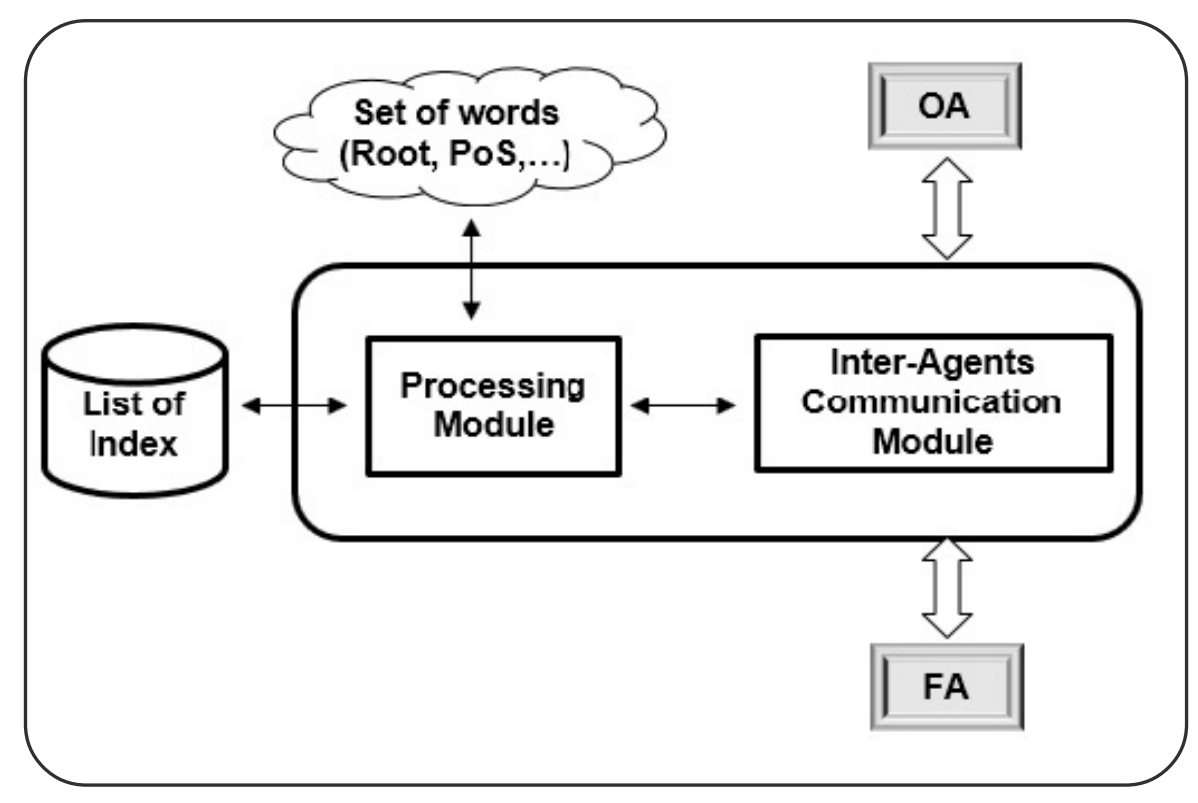

Figure 11. The architecture of Indexing Agent(IA)

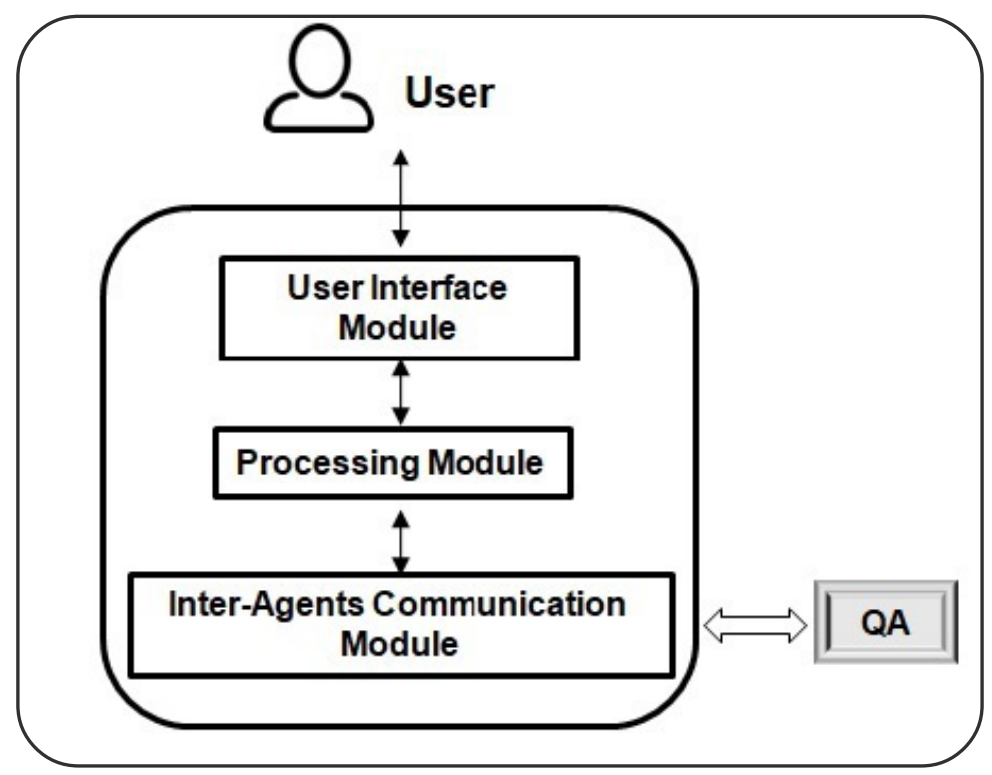

Figure 12. The architecture of Graphical Interface Agent(GIA) 


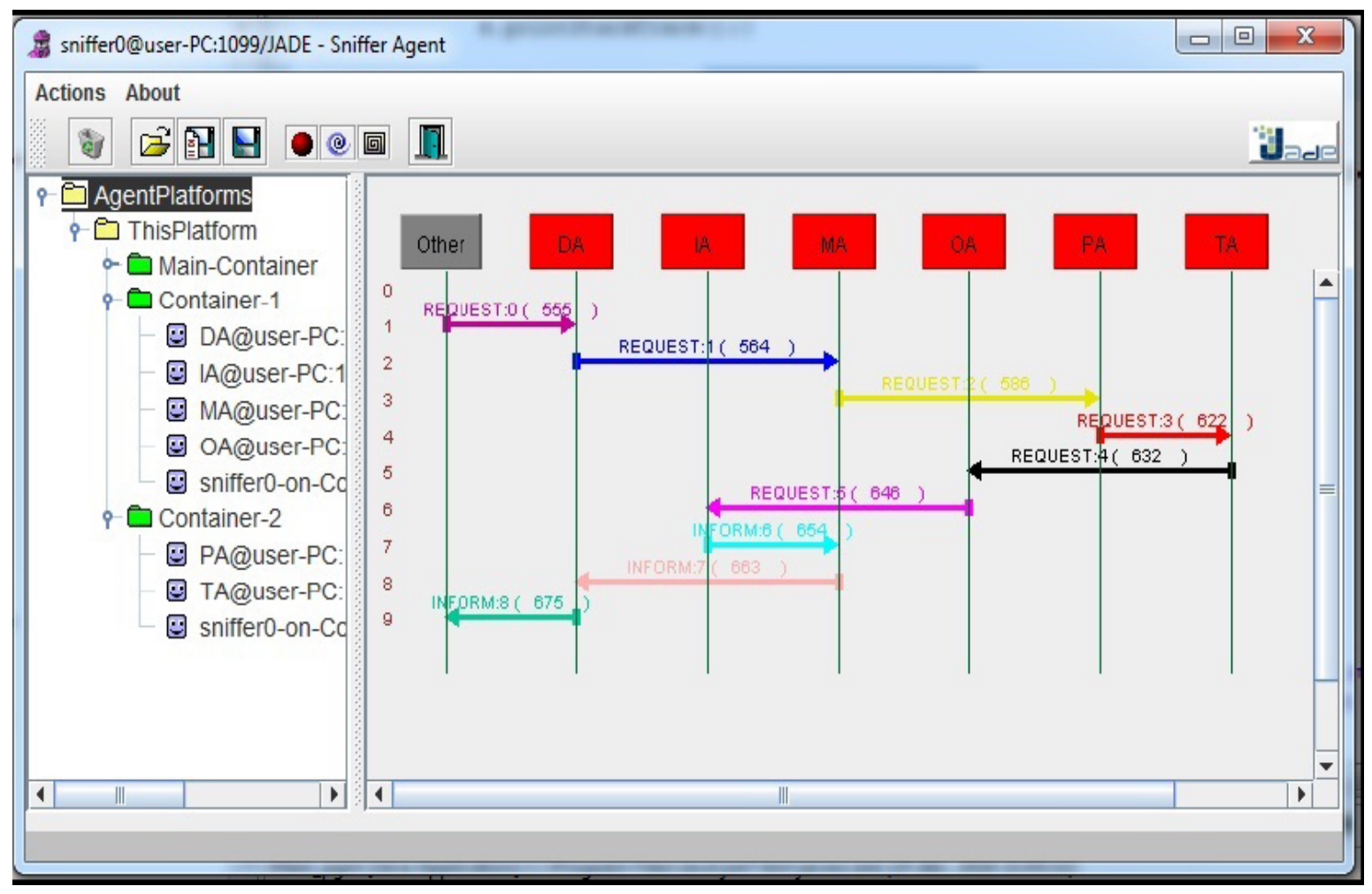

Figure 13. Agents communication for indexing and filtering the Documents

set of Arabic documents, which will be indexed by the system.

2. The DA sends a request for indexing the documents to the MA that is acquainted with.

3. The MA creates four agents to process these documents: PA, TA, OA, and IA. At the first, it contacts the PA to start the pre-processing of the documents.

4. The PA calls upon the TA to find the PoS of each word in the documents.

5. The TA sends to the OA a message requesting them for the semantic process.

6. The OA sends the list of the index extracted from Ara bic documents to the IA after the semantic process.

7. The IA sends back the end of the indexing process to the MA.

\section{The MA sends answers to the DA.}

\section{Semantic Query Indexing (SQI)}

In this scenario, a user runs a query in the form of a sentence written in Arabic via the graphical user interface provided by the IGA agent. This agent passes the request to the QA agent, which will process it and send the result to the MA agent. The MA agent will create 4 agents (PA, $\mathrm{TA}, \mathrm{IA}$, and FA in this order) to perform indexing and filtering operations. In doing so, it also sends the acquired data to the PA agent to accomplish its work. Each agent will send its results to the next agent as it is explained in the previous scenario. In this case, the MA agent coordinates between the DA agent and the QA agent to initiate parallel indexing with filtering processing. In this case, the $\mathrm{Al}$ agent sends a message to the FA agent to lunch the document filtering operation in order to find the relevant documents related to the request. The FA then sends back the result to the Query agent who has been waiting for the answer. Then, the Query Agent will pass them to the GIA agent for displaying them to the user. This scenario is illustrated in Figure 14.

\section{Experiments and Results}

For test data, we have faced difficulty to find an Arabic dataset to use it in the experimental and evaluation phase due to the lack of Arabic resources. Therefore, we combine two types of dataset, which are: Semantic Textual Simulation (STS)[52] and Open Source Arabic Corpora (OSAC)[49]. The first dataset includes Arabic as a part of Semantic

Textual Simulation (STS) resources for trial, training and evaluation data.In order to measure effectively the performance of our system, We have used 67 pairs are chosen from 368 pairs of Arabic sentences from STS 2017 Evaluation Sets v1.1. The data set contains four fields as follows: ID (unique identifier for each pair), STS score (a number between 0 and 5.), first sentence and second sentence. The pairs of Arabic sentences were manually translated from English by an Arabic expert. The STS 


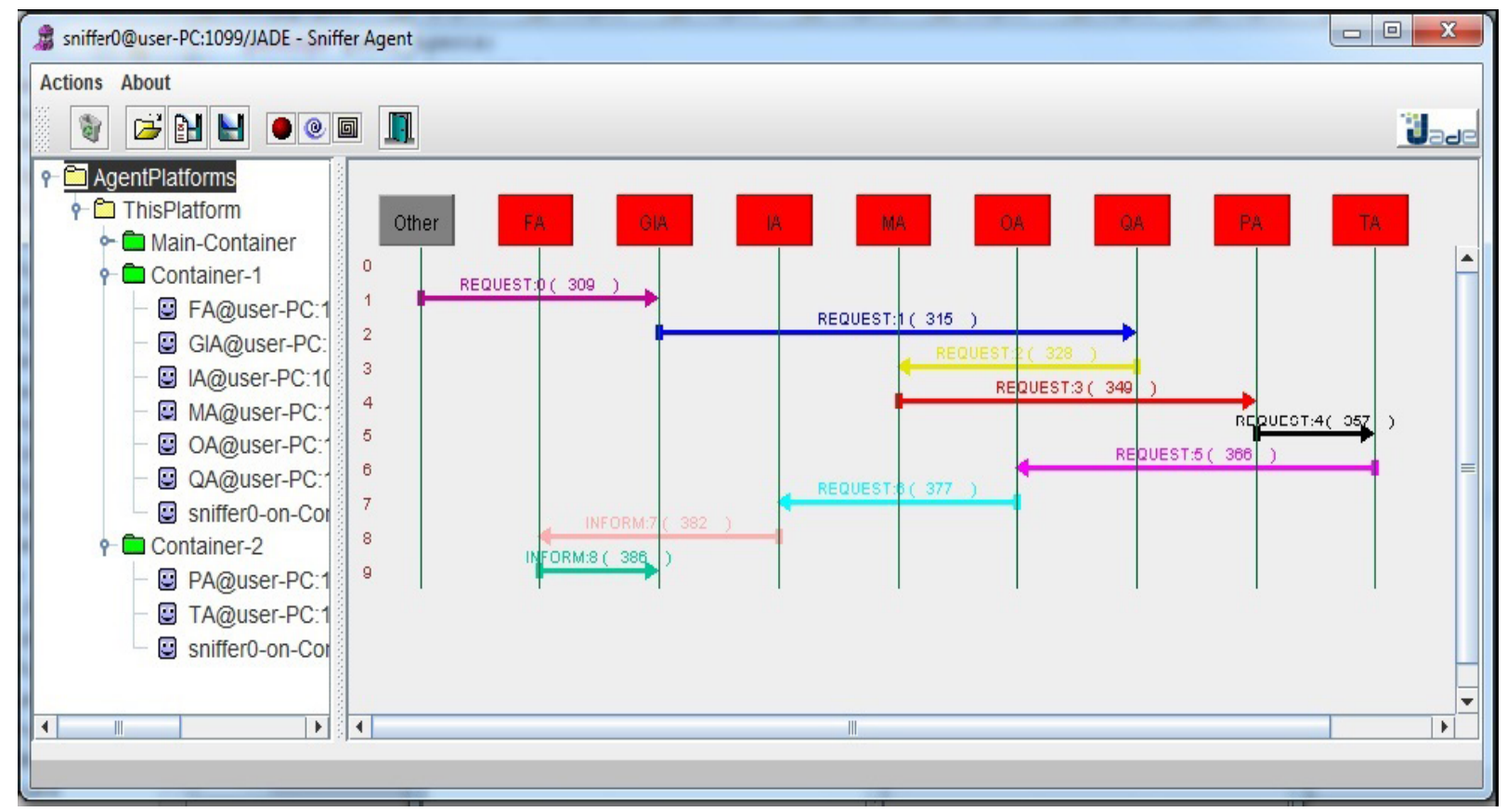

Figure 14. Agents communication for indexing and filtering the Query

\begin{tabular}{|c|c|c|c|c|c|c|c|c|c|c|c|c|c|}
\hline $\mathbf{N}$ & Folder Name & $\begin{array}{l}\text { S i z e } \\
\text { MO }\end{array}$ & \begin{tabular}{|l|} 
Total \\
Documents
\end{tabular} & $\begin{array}{l}\text { Total } \\
\text { words }\end{array}$ & NB Verb & NB Noun & NB Adj & Total & $\begin{array}{c}\text { Verb } \\
\%\end{array}$ & $\begin{array}{c}\text { Noun } \\
\%\end{array}$ & $\begin{array}{c}\text { Adj } \\
\%\end{array}$ & Total \% & Time Process \\
\hline 1 & Astronomy & 3.25 & 557 & 590070 & 32795 & 163208 & 40432 & 236435 & 6 & 28 & 7 & 40 & $1 \mathrm{~m} 5 \mathrm{~s}$ \\
\hline 2 & Cook & 4 & 2373 & 756310 & 32758 & 248792 & 41883 & 323433 & 4 & 33 & 6 & 43 & $1 \mathrm{~m} 16 \mathrm{~s}$ \\
\hline 3 & Economy & 19.3 & 3102 & 3471816 & 178692 & 978531 & 255854 & 1413077 & 5 & 28 & 7 & 41 & $3 \mathrm{~m} 6 \mathrm{~s}$ \\
\hline 4 & Family & 35.8 & 3608 & 6727387 & 426936 & 1851754 & 306109 & 2584799 & 6 & 28 & 5 & 38 & $5 \mathrm{~m} \mathrm{36s}$ \\
\hline 5 & Health & 18.6 & 2296 & 3424805 & 159205 & 974334 & 240939 & 1374478 & 5 & 28 & 7 & 40 & $2 \mathrm{~m} 44 \mathrm{~s}$ \\
\hline 6 & History & 46.3 & 3233 & 8512464 & 507789 & 2399708 & 461554 & 3369051 & 6 & 28 & 5 & 40 & $6 \mathrm{~m} 42 \mathrm{~s}$ \\
\hline 7 & Low & 8.2 & 944 & 1543946 & 70660 & 424295 & 90436 & 585418 & 5 & 27 & 6 & 38 & $1 \mathrm{~m} 21 \mathrm{~s}$ \\
\hline 8 & Religion & 19.8 & 3171 & 3662525 & 178888 & 1188634 & 165674 & 1533196 & 5 & 32 & 5 & 42 & $3 \mathrm{~m} 14 \mathrm{~s}$ \\
\hline 9 & Sport & 9.75 & 2419 & 1716185 & 95066 & 553815 & 111741 & 760622 & 6 & 32 & 7 & 44 & $1 \mathrm{~m} 55 \mathrm{~s}$ \\
\hline 10 & Stories & 12.9 & 726 & 2489287 & 206376 & 663572 & 101039 & 970987 & 8 & 27 & 4 & 39 & $3 \mathrm{~m} 4 \mathrm{~s}$ \\
\hline Total & 10 folders & 177.9 & 22429 & 32894795 & 1889165 & 9446643 & 1815688 & 13151496 & 40 & 6 & 29 & 6 & $29 \mathrm{~m} 1 \mathrm{~s}$ \\
\hline
\end{tabular}

Table 5. Statistical description of the dataset used in our work (OSAC)

score is the average of the values manually provided by five annotators. It is a floating number between "0" (indicating that the meaning of the sentences is completely independent) and " 5 " (indicating meaning equivalence). The second one, it contains ten categories(folders) of Arabic text document as presented in Table 5 OSAC Arabic corpus is collected from multiple websites. It includes 22,429 text documents, which each text document belongs to 1 of 10 categories.

The chosen pairs have at least 2.5 scores, which means that they are semantically similar. After that, we insert randomly these sentences in the OSAC documents to form a dataset with relevant documents. Here, we want to experiment the accuracy and execution time of index- ing Arabic documents to answer the queries user.

In order to evaluate our semantic indexing of Arabic documents, we conducted two types of approaches for filtering information according to the user's query. These approaches are: First, filtering based on an ontology. In which, we have indexed semantically the documents and also the query, where the proposed ontology (SchemNet) is used to extend each sentences (see algorithm'1). Second, filtering based on Apache Lucene [6]. For both approaches, a list of 60 queries (sentences) was used.

Apache Lucene[6] is a free and open-source information retrieval software library, originally written completely in Java. It provides Javabased indexing and search technol- 
ogy, as well as spellchecking, hit highlighting and advanced analysis/tokenization capabilities. The Apache Lucene has some important features, such as: Small footprint in RAM, Fast indexing, Size of the index is small compared to the size of the documents (about 20-30). Lucene is based in the indexing process on what is called an inverted index because it reverses the usual correspondence of a document with the terms it contains. The reverse index provides the mechanism for scoring search results: if a number of search terms all correspond to the same document, then this document is likely to be relevant. It supports indexing and searching of Arabic documents.

\subsection{Evaluation Metrics}

We tend to use accuracy to measure the performance of our system in comparison to other works. Although suitable metrics are available for many tasks, we have found that metrics such as recall and precision may seem the best tool for our task, which is the semantic indexing for information retrieval. The evaluation metrics used in our work for measuring the performance of semantic indexing is developed by our approach and the Lucene-based approach. All metrics are based on results obtained after running task. The metrics are presented as follow:

Considering the correct number selected relevant documents, which are in fact relevant, noted TP, the incorrect number selected relevant documents, noted FP, the number of non-selected documents that are actually relevant, noted FN, and the number of non-selected documents that are actually not relevant, noted TN.

The precision, recall, and F-measure are defined as follows:

$$
\begin{gathered}
\text { Precision }=\frac{T P}{(T P+F P)} \\
\text { Recall }=\frac{T P}{(T P+F N)} \\
F-\text { measure }=2 * \frac{\text { Precision } * \text { Recall }}{\text { Precision }+ \text { Recall }}
\end{gathered}
$$

Where:

- Recall: The ability of a classification model to identify all relevant documents. It is defined as the number of selected relevant documents divided by the total number of existing relevant documents.

- Precision: The ability of a classification model to return only relevant documents. It is defined as the number of relevant selected documents divided by the total number of documents selected.

- F-measure: Single metric that combines recall and pre- cision using the harmonic mean.

\section{Discussion}

In this section, we will make a comparison between Our approach and Apache Lucene's approach. Unlike the Lucene approach, our approach is based on the ontology SchemNet which allows us to perform semantic or meaning-based indexing, rather than word-based indexing. The meanings of words in SchemNet are given by several relationships that later define for example: synonym, pattern, and type,... etc.

The results presented in Figure 15 show that the indexing method proposed in this paper has the best rate compared to Precision/Recall.

Based on the F-measure score as shown in Table 6, the overall best approach occurs by our proposed system, in comparison with the other method mentioned in this document. The ontological method used (SchemNet) provides better accuracy and recovery compared to the Lucene method.

Lucene is a powerful software but it gives a lot of irrelevant proposed responses to the user, which implies a very high noise level as shown in table 6 . But for silence, both approaches give almost all the relevant documents that respond to the user's request.

Compared to the execution time in the process of indexing and filtering documents, Lucene gets a better time with $243614 \mathrm{~ms}$, unlike our approach which is achieved in ten (10) hours. We note that, the MSA can be very useful in the distributed system to obtain a short execution time, especially when using mobile agents to select another node (system) to execute the document indexing process. This allows parallel execution with multiple platforms.

\section{Conclusion and Future Work}

In this paper, we have constructed a new ontology based on schemes and their meaning (SchemNet). We use this ontology to index Arabic documents. The MAS architecture is presented to improve our system performance especially to reduce the execution time consumed in the various levels in the Arabic document indexing process. We adopted the linguistic approach, which can provide a good report of relevance compared to other approaches. We have developed a filtering system based on a formula that has been proposed in this paper. This formula allows us to calculate the semantic similarity between each indexed sentence of a document with the user's request, which has been indexed in the same way as well.

All the aspects studied here have shown that ontological consensus provides a semantic basis on which an index system can be built; for us, it is clear that the ontology 


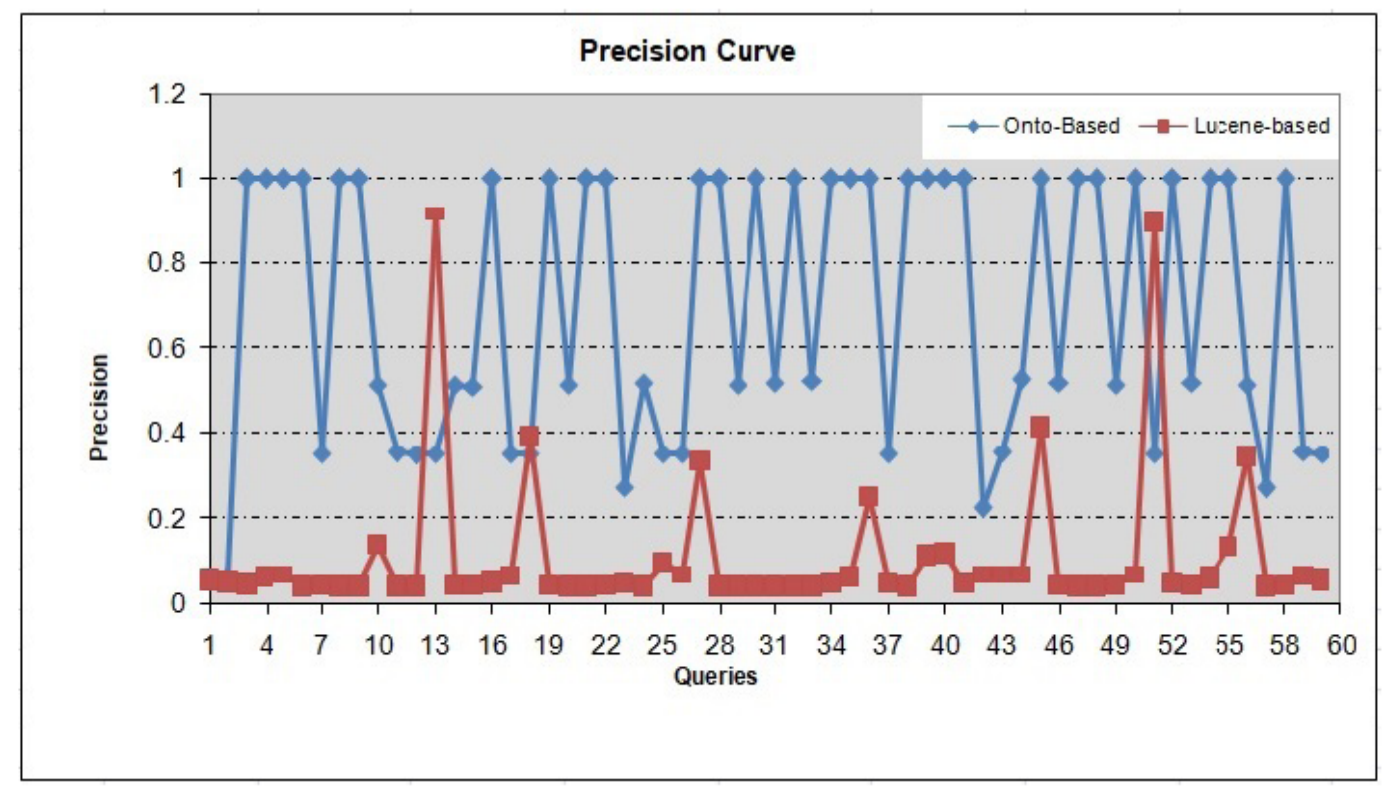

Figure 15. Metrics evaluation results

\begin{tabular}{|l|l|l|l|}
\hline Approaches & Precision & Recall & F-measure \\
\hline Ontology Approach & 0687 & 0.971 & 0.768 \\
\hline Lucene Approach & 0.111 & 0.975 & 0.170 \\
\hline
\end{tabular}

Table 6. Metrics evaluation results

paradigm can provide the keystone for designing mechanisms for information retrieval in the field of social cooperation (using MAS) with semantic context.

Therefore, there is still much to be done in the future, and the most important of our research is to extend the proposed ontology to support other types of Arabic documents.

\section{References}

[1] Abdelali, A., et al. (2016). Farasa: A Fast and Furious Segmenter for Arabic. In: NAACL- 2016, http:// qatsdemo.cloudapp.net/farasa/, last accessed at 27/09/ 2018.

[2] Abdeslem, D., Benslimane, S. M. (2015). Semantic Indexing of Web Documents Based on Domain Ontology. International Journal of Information Technology and Computer Science 7, p. 1-11. doi: 10.5815/ijitcs.2015.02.01.

[3] Abderrahim, M., et al. (2013). Using Arabic Wordnet for semantic indexation in information retrieval system.

[4] Alaeddine, et al. (2015). Semantic indexing of Arabic texts for information retrieval system. International Journal of Speech Technology. doi: 10.1007/s10772-015-93073. url: http://dx.doi. org/10.1007/s10772-015-9307-3.
[5] Abouenour, L. et al. (2013). On the evaluation and improvement of Arabic WordNet coverage and usability . Language Resources and Evaluation, 47 (3) 891-917.

[6] Addagada, S. (2007). Indexing and Searching Document Collections using Lucene. In: University of New Orleans Theses and Dissertations. 1070. https:// scholarworks.uno.edu/td/1070.

[7] Al-Arfaj, A. and Abdulmalik A. (2013). Towards Ontology Construction from Arabic Texts- A Proposed Framework. In: Proceeding of The 14th IEEE International Conference on Computer and Information Technology (CIT 2014) p. 737-742.

[8] Al-Molijy, A. et al. (2012). Indexing of Arabic documents automatically based on lexical analysis. International Journal on Natural Language Computing (IJNLC) 1 , (1).

[9] Al-yahya, M. et al. (2015). Ontology-Based Semantic Annotation of Arabic Language Text. In: Modern Education and Computer Science, 2015, 7, 53- 59, no. -59, 2015. Published Online July 2015 in MECS (http:// www.mecs- press.org/).

[10] Al-Zamil, M. G.H., Al-Radaideh, O. (2014). Automatic extraction of ontological relations from Arabic text. Journal of King Saud University Computer and Information Sciences, 26 (4) 462- 472. 
[11] Al-Zoghby, A. M., et al. (2018). Semantic RelationsExtraction and Ontology Learning from Arabic Texts. A Survey. In: Shaalan K., Hassanien A., Tolba F. (eds) Intelligent Natural Language Processing: Trends and Applications. Studies in Computational Intelligence, vol 740. Springer, Cham.

[12] AlAgha, I., and Abu-Taha, A. (2015). AR2SPARQL : An Arabic Natural Language Interface for the Semantic Web. International Journal of Computer Applications (0975 8887) 125 (6) September 2015.

[13] Alami, N., et al. (2016). Impact of stemming on Arabic text summarization. In: 4th IEEE International Colloquium on Information Science and Technology (CiSt), Tangier, 2016, p. 338- 343. doi: 10.1109/ CIST.2016.7805067.

[14] Alnahdi, A., 2017. Building Bilingual Algorithm English-Arabic Ontology For Cognitive Applications. In: 2017 IEEE 1st International Conference on Cognitive Computing. https://doi.org/10.1109/IEEE.ICCC.2017.22.

[15] Almasoud, A. M., and Al-Khalifa, H. S. (2012). SemSignWriting : A Proposed Semantic System for Arabic Text-to-SignWriting Translation. Journal of Software Engineering and Applications, 5 August, p. 604-612.

[16] Alromima, W. et al. (2016). Ontology-based Query Expansion for Arabic Text Retrieval. In: (IJACSA) International Journal of Advanced Computer Science and Applications, 7 (8) 223-230.

[17] Atlam, E. and El-barbary , O.G. (2014). Arabic document summarization using fa fuzzy ontology. International Journal of Innovative Computing, Information and Control. 10 (4) August 2014 ICIC, vol. 10.

[18] Bazzi, M. S.El., et al. (2016). Indexatioes: etat de l'art. In: E-Ti: E-Review in Technologies Information.

[19] Bazzi, M.S.El., et al. (2018). Toward a Complex System for Context Discovery to Index Arabic Documents. Journal of Computers. 13 (8) 955-962.

[20] Belkredim, F. Z., and El Sebai, A. (2009). An Ontology Based Formalism for the Arabic Language Using Verbs and their Derivatives. In: Communications of the IBIMA, vol. 11, 44-52, 2009.

[21] Benaissaa, B.E., et al. (2015). Building Arabic ontology from texts. In: The International Conference on Advanced Wireless, Information, and Communication Technologies (AWICT 2015), vol. 00.

[22] Black, W., et al. (2006). Introducing the Arabic WordNet Project. Introducing the Arabic WordNet Project, In: Proceedings of the Third International WordNet Conference. Sojka, Choi, Fellbaum and Vossen eds.

[23] Bougar, M., Elhoussaine, Z. (2019). Stemming Algorithm for Arabic Text Using a Parallel Data Processing. In: Third International Congress on Information and Communication Technology, Advances in Intelligent Systems and Computing 797Springer Nature Singapore Pte-
Ltd. 2019. doi: 10.1007/978-981-13-1165-9 23.

[24] Elkateb, S., et al. (2006). Building aWordNet for Arabic. In: Proceedings of the Fifth International Conference on Language Resources and Evaluation, Genoa, Italy.

[25] Fabien, G. (2002). Distributed Artificial Intelligence And Knowledge Management: Ontologies And MultiAgent Systems. In: Scientific Philosopher Doctorate Thesis In Informatics, INRIA and University of Nice - Sophia Antipolis Doctoral School of Sciences and Technologies of Information and Communication (S.T.I.C.)

[26] Ferber, J., and Olivier, G. (1998). A meta-model for the analysis and design of organizations in multi-agent systems. In: IEEE Computer Society, Proc. 3rd ICMAS, 128-135.

[27] FIPA, (2001). Foundation for Intelligent Physical Agents, FIPA Specifications. (Available from http:// www.fipa.org/).

[28] Ghalib, A.N.. Nazlia O. (2014). Arabic Keyphrases Extraction Using a Hybrid of Statistical and Machine Learning Methods. In: International Conference on Information Technology and Multimedia (ICIMU), November 18 20, 2014, Putrajaya, Malaysia.

[29] Gruber, R. T. (1993). A Translation Approach to Portable Ontology Specifications. Knowledge Systems Laboratory, Computer Science Department Stanford. University Stanford, California 94305, vol. 5, p. 199-220.

[30] Guirat, S. et al. (2016). A Hybrid Model for Arabic Document Indexing. In: 17th IEEE/ACIS International Conference on Software Engineering, Artificial Intelligence, Networking and Parallel/Distributed Computing (SNPD), Shanghai, 2016, p. 109-114.

[31] Hadj, H. M. (2009). Approche ontologique pour la modlisation smantique, l'indexation et l'interrogation des documents Coraniques. In: Computer science memory schoolmaster, School of Computer Science, Oued-Smar, Algeria.

[32] Harrag, F.. Al-Nasser, A. (2014). Using association rules for ontology extraction from a Quran corpus. In: 5th International Conference on Arabic Language Processing (CITALA 2014), Oujda, Morocco.

[33] Hitzler, P. et al. (2009). Foundations of Semantic Web Technologies. Available from http://www.semanticweb-book.org, last accessed on february 16th, 2017 (22:40).

[34] Ishkewy, H. et al (2014). Azhary: An Arabic Lexical Ontology. International Journal of Web \& Semantic Technology (IJWesT), 5 (4) https://doi.org/10.5121/ ijwest.2014.5405.

[35] Bellifemine., Fabio., Agostino Poggi., and Giovanni Rimassa. (2001). Developing multiagent systems with a FIPA-compliant agent framework. Software Practice \& Experience, 2001, 31. 103-128.

[36] Jarrar, M. (2011). Building a Formal Arabic Ontology( 
Invited Paper). In: Proceedings of the Experts Meeting on Arabic Ontologies and Semantic Networks. Alecso, Arab League. Tunis, April 26-28, 2011.

[37] Jaafar, Y., et al. (2017). Enhancing Arabic stemming process using resources and benchmarking tools. In: Journal of King Saud University - Computer and Information Sciences, 29 (2) April 2017, 264-170. doi:10.1016/ j.jksuci.2016.11.010.

[38] Jaouad, M. (2010). A Large Coverage Verb Lexicon For Arabic. In: Proceedings of the 7th conference on International. Language Resources and Evaluation (LREC) (2010), Valetta, Malta.

[39] Jaouad, M. (2011). Classifying Arabic verbs using sibling classes. In: Proceedings of the 9th International Conference on Computational Semantics, Association for Computational Linguistics. p. 355-359, Oxford, UK.

[40] Karkar, A. G., et al. (2014). An Arabic Ontology-based Learning System for Children with Intellectual Challenges. In: IEEE Global Engineering Education Conference (EDUCON), no. April, pp. 670-675.

[41] Keskes, I. (2018). Discourse Analysis of Arabic Documents and Application to Automatic Summarization. In: Doctoral thesis, Universit de Sfax, 2015. Retrieved from thesesups.upstlse. fr/2741/1/2015TOU30023.pdf. Last accessed at 09 Nov 2018.

[42] Khan, H. U., et al. (2013). Ontology Based Semantic Search in Holy Quran. International Journal of Future Computer and Communication, 2 (6) 570-575.

[43] Khoja, S., and Garside R. (1999). Stemming Arabic Text. Computing Department, Lancaster University, Lancaster.

[44] Levin, B. (1993). English Verb Classes and Alternations. A Preliminary Investigation. Chicago and London: The University of Chicago Press.

[45] Moawad, I. F., et al. (2010). Ontology-based Architec ture for an Arabic Semantic Search. In: Engine, The Tenth Conference on Language Engineering (ESOLEC'2010),no. November 2010.

[46] Reham, M., et al. (2015). Al-Bayan A Knowledgebased System for Arabic Answer Selection. In: Proceedings of the 9th International Workshop on Semantic Evaluation (SemEval 2015), Denver, Colorado, no. SemEval, pp. 226-230.

[47] Nasri, M., et al. (2016). A novel approach for semantic analysis of Arabic texts using an Arabic ontology and Conceptual Graphs. DOI: 10.13140/RG.2.1.1493.4646.

[48] Raghib, A. (2016). Morphological analysis of the com- ponents of the Arabic words: study of language computing. Journal of the generation of literary and intellectual studies, 3 (21)111-122.

[49] Saad, M. K., Ashour, W. (2010). OSAC: Open Source Arabic Corpora. In: the 6th International Conference on Electrical and Computer Systems (EECS'10), Nov 2526, 2010, Lefke, North Cyprus.

[50] Saadane, H. (2013). A linguistic approach for knowledge extraction from an Arabic text. In: Proceedings of RECITAL 2013, ATALA, p. 124-137.

[51] Shamsuzzaman, S., et al. (2016). Applying Ontological Modeling on Quranic Nature Domain. In: 7th International Conference on Information and Communication Systems (ICICS).

[52] SemEval-2017 Task 1. Semantic Textual Similarity. Available from http://alt.qcri.org/semeval2017/task1/ index. php?id=dataand-tools last accessed on Septemer 05th.

[53] Sheker, M., et al. (2016). Domain-Specific OntologyBased Approach For Arabic Question Answering. Journal of Theoretical and Applied Information Technology. vol. 83, no. 1.

[54] Stumme, G., et al. (2006). Semantic web mining: State of the art and future directions. Web semantics: Science, services and agents on the world wide web, 4 (2) 124-143.

[55] Suryana, N., et al. (2018). Quran Ontology: Review on Recent Development and Open Research Issues. Journal of Theoretical and Applied Information Technology 96 (3)568-58.

[56] Uschold, M., King, M., (1995). Towards a methodology for building ontologies. Citeseer 1995.

[57] Ta'a, A., et al. (2013). Al-Quran Themes Classification Using Ontology. In: The 4th International Conference on Computing and Informatics (ICOCI 2013).

[58] Taa, A., et al. (2016). Ontology-Based Approach for Knowledge Retrieval in Al-Quran Holy Book. International Journal of Computational Engineering Research (IJCER), 8-15.

[59] Weaam, A., Saidah, S. (2016). Ontology Population From Quranic Translation Texts Based On A Combination of Linguistic Patterns And Association Rules. Journal of Theoretical and Applied Information Technology, $86(2)$.

[60] Yauri., A. et al. (2013). Quranic Verse Extraction base on Concepts using OWL-DL Ontology. In: Research Journal of Applied Sciences, Engineering and Technology. vol. 6, p. 4492-4498. 